Annales Geophysicae (2001) 19: 189-204 (C) European Geophysical Society 2001

\title{
A classification of spectral populations observed in HF radar backscatter from the $E$ region auroral electrojets
}

\author{
S. E. Milan and M. Lester \\ Department of Physics and Astronomy, University of Leicester, Leicester LE1 7RH, UK.
}

Received: 27 September 1999 - Revised: 7 December 2000 - Accepted: 15 December 2000

\begin{abstract}
Observations of HF radar backscatter from the auroral electrojet $\mathrm{E}$ region indicate the presence of five major spectral populations, as opposed to the two predominant spectral populations, types I and II, observed in the VHF regime. The Doppler shift, spectral width, backscatter power, and flow angle dependencies of these five populations are investigated and described. Two of these populations are identified with type I and type II spectral classes, and hence, are thought to be generated by the two-stream and gradient drift instabilities, respectively. The remaining three populations occur over a range of velocities which can greatly exceed the ion acoustic speed, the usual limiting velocity in VHF radar observations of the $\mathrm{E}$ region. The generation of these spectral populations is discussed in terms of electron density gradients in the electrojet region and recent non-linear theories of $\mathrm{E}$ region irregularity generation.
\end{abstract}

Key words. Ionosphere (ionospheric irregularities)

\section{Introduction}

At $\mathrm{F}$ region altitudes, both ions and electrons are said to be magnetised; their gyrofrequencies exceed their collision frequencies, $v_{e}<\Omega_{e}$ and $v_{i}<\Omega_{i}$, and so both move with a velocity $\boldsymbol{E} \times \boldsymbol{B} / B^{2}$, where $\boldsymbol{B}$ is the Earth's magnetic field and $\boldsymbol{E}$ is the convection electric field imposed by the magnetosphere. Plasma instability mechanisms operating in the F region, primarily the gradient drift instability (Maeda et al., 1963; Knox, 1964), generate field-aligned ionospheric plasma density perturbations or irregularities with a variety of scale-lengths from submetre to kilometres. As these irregularities are thought to drift with the bulk plasma motion, the Doppler shift imposed on coherent backscatter (radar aurora) from the $\mathrm{F}$ region gives an estimate of the line-of-sight component of the convection speed. HF radars, such as those which comprise SuperDARN (Greenwald et al., 1995), exploit the ionospheric refraction experienced in the 10 to 30

Correspondence to: S. E. Milan (steve.milan@ion.le.ac.uk)
MHz radio band to achieve orthogonality with $\boldsymbol{B}$, a condition necessary for the observation of backscatter from fieldaligned irregularities. At $10 \mathrm{MHz}$, the Bragg condition is satisfied for irregularities with a wavelength of $15 \mathrm{~m}$, i.e. in the decametre regime. Several studies have demonstrated that, at least to the first order, decametre-scale irregularities in the $\mathrm{F}$ region do indeed drift with the $\boldsymbol{E} \times \boldsymbol{B}$ velocity (Davies et al., 1999, and references therein).

At $\mathrm{E}$ region altitudes, below, for example, $130 \mathrm{~km}, v_{i}>$ $\Omega_{i}$, ions are said to be unmagnetised, and the ion population is constrained to move with the neutral atmosphere, which is often assumed to be stationary. The disparity in ion and electron velocities results in a current. This current is especially intense where the $\mathrm{E}$ region electron density or conductivity is high, as in the eastward and westward auroral electrojet regions. The instability mechanisms operating in this collisional regime are more complex than at $\mathrm{F}$ region altitudes, with, in addition to the gradient drift instability, the twostream or Farley-Buneman instability (Farley, 1963; Buneman, 1963) being of major importance. The spectral characteristics of coherent backscatter from the $\mathrm{E}$ region has been studied extensively with VHF radars (see Haldoupis et al., 1989, and references therein), which are sensitive to metrescale irregularities. Theoretical work concerning the instability mechanisms responsible for generating these irregularities in this wavelength regime can now qualitatively explain the characteristics of most spectra observed. In particular, narrow spectra with velocities near the local ion-acoustic speed $C_{s} \approx 400 \mathrm{~m} \mathrm{~s}^{-1}$ (called type I spectra) are understood in terms of the two-stream instability, and slower, broader spectra (type II) are thought to be generated by the gradient drift instability. In VHF radar measurements, the ionacoustic speed is found generally to be an upper limit to the range of velocities observed, though the magnitude of $C_{s}$ and hence the phase velocity of type I spectra increases under high electric field conditions (Robinson, 1986).

$\mathrm{HF}$ radar observations of the $\mathrm{E}$ region have received less attention (e.g. Villain et al., 1987, 1990; Hanuise et al., 1991; Milan and Lester, 1998, 1999; Milan et al., 2000). HF radars 
allow E region instability mechanisms to be studied in a new wavelength regime where, it will be demonstrated, a greater variety of spectral types are found and Doppler shifts near $1000 \mathrm{~m} \mathrm{~s}^{-1}$ are regularly observed. The present paper aims to provide an overall description of the spectral characteristics of backscatter originating in the auroral electrojet regions, predominantly from $\mathrm{E}$ region altitudes, as observed by the CUTLASS Iceland coherent HF radar. Five main populations of spectra are identified, as defined by their velocity, spectral width, backscatter power and flow angle distributions. This paper presents a context within which future studies can discuss the instability mechanisms and propagation geometry responsible for $\mathrm{E}$ region backscatter generation.

\section{The CUTLASS Iceland coherent HF radar}

The CUTLASS (Co-ordinated UK Twin-Located Auroral Sounding System) bistatic coherent HF radar system forms the eastern-most portion of the northern hemisphere SuperDARN chain (Greenwald et al., 1995). It comprises two radars, of which the CUTLASS Iceland radar, located at Pykkvibær $\left(63.8^{\circ} \mathrm{N}, 20.5^{\circ} \mathrm{W}\right)$, is the focus of the present study. This radar is similar in construction to the other SuperDARN radars, and only the most relevant details are included here. The radar scans through 16 azimuthal pointing directions, separated by approximately $3.2^{\circ}$, and distributed symmetrically about the radar boresite of $30^{\circ}$ (east of geographic north). In the normal scan mode of the radar, the 16 beams are sounded with a dwell time of $7 \mathrm{~s}$, producing field-of-view maps every 2 minutes of backscatter with an azimuthal coverage of over $50^{\circ}$. Typically, 75 range gates are sampled for each beam (hence, a total field-of-view containing 1200 cells), with a pulse length of $300 \mu$ s, corresponding to a gate length of $45 \mathrm{~km}$, and a lag to the first gate of $1200 \mu \mathrm{s}$ $(180 \mathrm{~km})$. The scan mode employed in the present study (referred to as the "myopic" scan mode) is a slight modification of this in that the pulse length is reduced to $100 \mu \mathrm{s}(15 \mathrm{~km})$ to provide high spatial resolution observations of the electrojet region, where $\mathrm{E}$ region scatter is most often observed (Milan and Lester, 1998). In this configuration, the field-of-view covers $10^{\circ}$ of magnetic latitude $\left(65^{\circ} \mathrm{N}\right.$ to $\left.75^{\circ} \mathrm{N}\right)$ and 1.5 hours of magnetic local time (MLT $\approx$ UT to UT +1.5 ). On occasions, the dwell time was reduced to $3 \mathrm{~s}$, reducing the scan time to approximately $50 \mathrm{~s}$, and hence, increasing the number of observations. In total, 321 hours of myopic observations were collected between February 1998 and March 1999; the period selected for the present study.

The radar can operate in the HF band between $8 \mathrm{MHz}$ and $20 \mathrm{MHz}$, though the observations of the present study were made at a radar operating frequency of approximately $10 \mathrm{MHz}$ (corresponding to an irregularity wavelength $\lambda \approx$ $15 \mathrm{~m})$. A 7 pulse scheme is transmitted and the spectral characteristics of the backscatter are determined directly from the resulting 17-lag auto-correlation function (ACF) collected at each range gate, as described by Hanuise et al. (1993). The power and spectral width of the backscatter is estimated from a Lorentzian or Gaussian fit to the decorrelation of the ACF, and the line-of-sight Doppler velocity from a least squares fit to the phase of the complex value of the ACF as a function of lag. Little difference was found between the Lorentzian and Gaussian estimates of spectral width and power, and hence, only the former are shown from this point onwards. We should note that the ACF analysis technique assumes that return echoes comprise only a single component. It is almost certain that some spectra are multi-component, but we cannot easily tackle this problem at the present time.

The object of this study is to investigate the characteristics of backscatter from $\mathrm{E}$ region irregularities, and hence $\mathrm{E}$ and F region backscatter, both routinely observed by the radar, must be distinguished. A previous investigation of HF radar observations of E region backscatter (Hanuise et al., 1991) accomplished this by assuming that all backscatter observed within $800 \mathrm{~km}$ range or so of the radar originated solely in the $\mathrm{E}$ region. The present study, however, employs the elevation angle at which the backscattered signal is observed to estimate the altitude from which the scatter originates. The elevation angle, $\Delta$, is determined through an interferometric technique, described more fully in Milan et al. (1997). The altitude, $h$, of the scatter volume can then be estimated assuming straight line propagation, i.e. ignoring the effects of refraction, with

$h=\left(R_{E}^{2}+2 R_{E} D \sin \Delta+D^{2}\right)-R_{E}$

where $D$ is the radar range of the backscatter and $R_{E}$ is the radius of the Earth. Refraction effects can become significant, and the straight line propagation assumption breaks down if backscatter occurs near the top of the E region. Simple ray-tracing indicates that in this case, $h$ tends to be an over-estimate of the true altitude of the scatter volume, usually by $10-20 \mathrm{~km}$, but up to $50 \mathrm{~km}$ in extreme cases. Unfortunately, the effects of refraction cannot be taken into consideration on a routine basis without a detailed knowledge of the $\mathrm{E}$ region electron density distribution. However, it will be demonstrated that this is not a major impediment to the present study.

\section{Observations}

The first task of the investigation is to distinguish between $\mathrm{E}$ region and $\mathrm{F}$ region backscatter. Figure 1 illustrates the occurrence distribution of backscatter altitude deduced by the interferometer from all myopic observations employed in this study. Two populations are observed in this distribution, with maxima near $120 \mathrm{~km}$ and $230 \mathrm{~km}$, identified as E region and $\mathrm{F}$ region backscatter, respectively. The $\mathrm{E}$ region population extends up to altitudes of $150 \mathrm{~km}$, though as discussed above, the high altitude tail of this population is thought to be due to over-estimation of the true altitude of scatter, due to a breakdown of the straight line propagation assumption. We take $150 \mathrm{~km}$ to be the demarcation altitude between backscatter identified as being of $\mathrm{E}$ region or $\mathrm{F}$ region origin. Clearly 


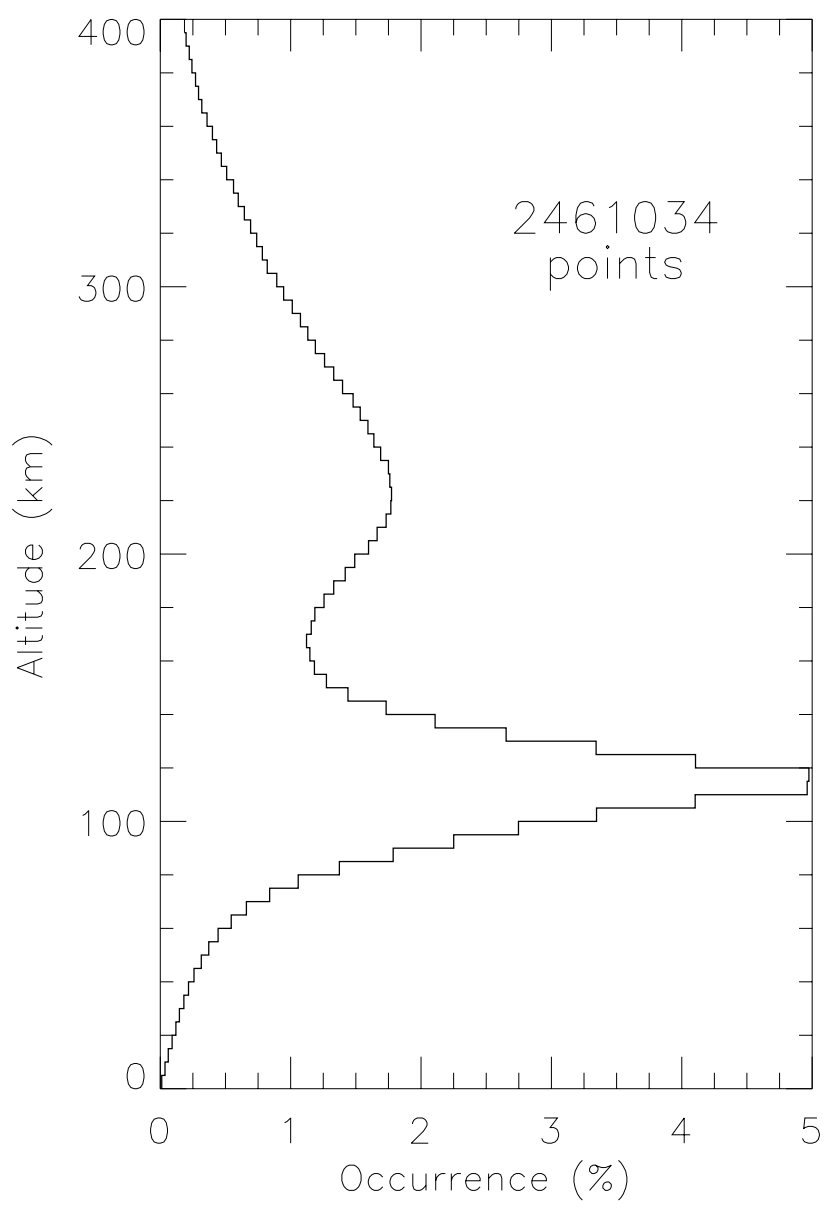

Fig. 1. The occurrence distribution of backscatter altitudes determined for all 321 hours of operation of the myopic radar mode. Altitude bins are $5 \mathrm{~km}$ wide.

some ambiguity is present near this demarcation altitude, but we find that this is not a significant problem for the purposes of the present study.

To test the success of this technique in discriminating between backscatter from the $\mathrm{E}$ and $\mathrm{F}$ regions, the occurrence distribution of backscatter as a function of line-of-sight velocity, or Doppler shift, from the two altitude regimes for all 321 hours of myopic observations is presented in Fig. 2. The data is binned in velocity increments of $40 \mathrm{~m} \mathrm{~s}^{-1}$. A power threshold of $3 \mathrm{~dB}$ has been applied to the data to remove the contribution of observations with a very low signal to noise ratio. In total, $1.0 \times 10^{6}$ and $1.4 \times 10^{6}$ points were identified as $F$ and $E$ region scatter, respectively. Both $E$ and $F$ region distributions have a broad occurrence maximum, centred on $0 \mathrm{~m} \mathrm{~s}^{-1}$. An overwhelming preponderance of observations have very low velocities indeed, between $\pm 20 \mathrm{~m} \mathrm{~s}^{-1}$, though this is not apparent in the figure as the occurrence scale has been selected to emphasise the more salient points of the distributions. This low velocity population is thought to be an undesired contribution from ground or meteor backscatter, which tends to have little or no imposed Doppler shift and

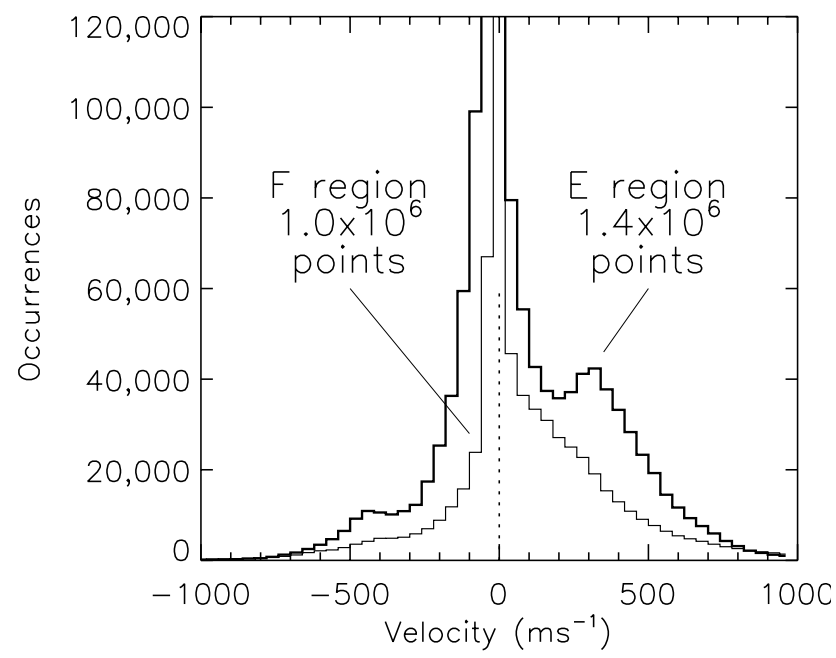

Fig. 2. Velocity occurrence distributions for all backscatter identified as of $E$ and $F$ region origin, a demarcation altitude of $150 \mathrm{~km}$ is employed. Velocity bins are $40 \mathrm{~m} \mathrm{~s}^{-1}$ wide.

low spectral width. Of the ionospheric scatter, a greater proportion of backscatter has positive rather than negative velocity, as most originated in the eastward as opposed to the westward electrojet region, as will be discussed below. Of particular interest are the shoulders which appear at approximately $\pm 350 \mathrm{~m} \mathrm{~s}^{-1}$ in the $\mathrm{E}$ region occurrence distribution, but which are much less discernible in the $\mathrm{F}$ region distribution. This is highly reminiscent of the distributions found by Hanuise et al. (1991) who employed the SHERPA HF radar to study the characteristics of $E$ region backscatter. The observation that our $\mathrm{F}$ region and $\mathrm{E}$ region occurrence distributions have different shapes, coupled with the similarity between our E region distribution and that of Hanuise et al., strongly suggests that the altitude discrimination employed in the present study works effectively in separating these two altitude regimes. In light of this, the remainder of this study will concentrate solely on the $\mathrm{E}$ region observations.

It is natural to compare the spectral characteristics of $\mathrm{E}$ region backscatter observed with HF radars with the wellknown characteristics of VHF radar observations. Such a comparison led Hanuise et al. (1991) to interpret HF radar E region backscatter with a line-of-sight velocity near 400 $\mathrm{m} \mathrm{s}^{-1}$ (close to the E region ion-acoustic speed) as type I spectra, or backscatter from irregularities produced by the two-stream instability. The remaining observations, with velocities below $400 \mathrm{~m} \mathrm{~s}^{-1}$, were identified with type II spectra, scattered from gradient drift irregularities. We follow this interpretation in the present study. Of special interest to us, though, are the spectral characteristics of backscatter with line-of-sight velocities significantly higher than the ambient value of the ion-acoustic speed, which forms a significant proportion of the present observations. To investigate these spectra in more detail we will turn to an examination of specific examples and case studies. 

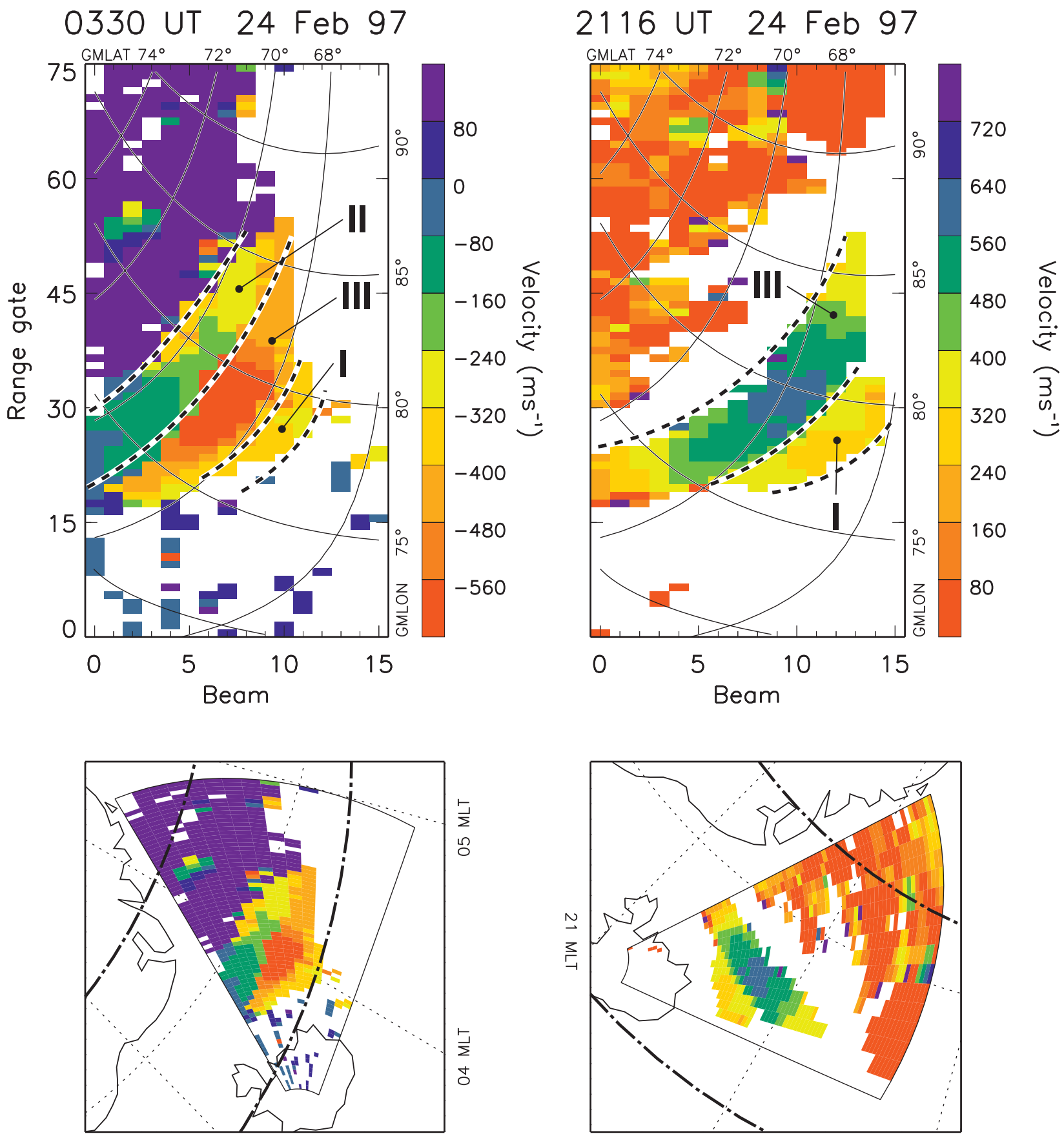

$03 \mathrm{MLT}$

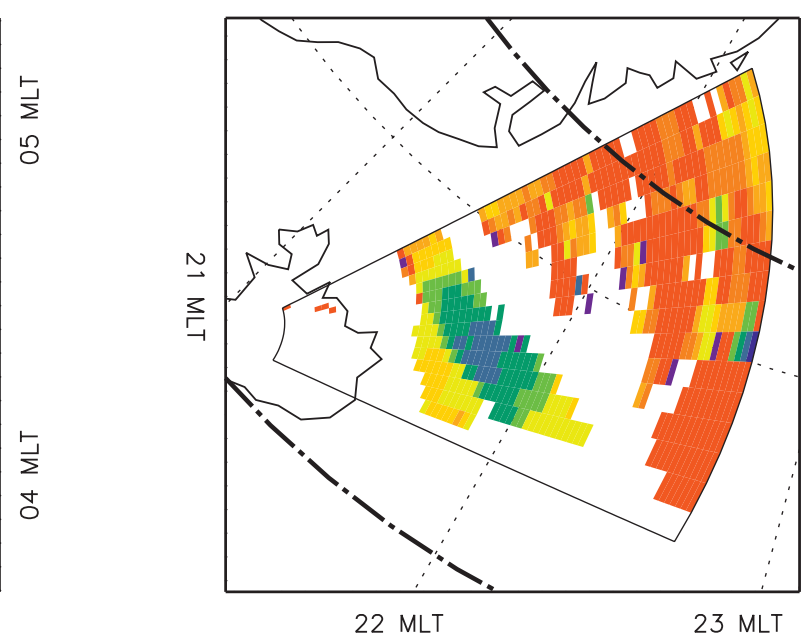

Fig. 3. Two examples of radar scans from the myopic campaign from 24 February 1997. (Upper panels) Curved lines indicate locii of geomagnetic latitude and longitude. Dashed lines demarcate different channels observed within the E region backscatter, labelled I, II, and III. (Lower panels) the same scans displayed on a magnetic latitude and magnetic local time coordinate system. The dot-dashed lines show the high and low latitude boundaries of the statistical auroral oval.

Figure 3 illustrates two typical examples of radar scans containing E region backscatter, from 0330 UT and 2116 UT, on 24 February 1997. Line-of-sight velocity is shown, which in SuperDARN observations is conventionally positive towards the radar and negative away from the radar. The colour scale in each case has been chosen to emphasise fea- tures within the E region backscatter (see below). In the upper panels, the radar scans are displayed in a rectilinear beam/gate format for clarity and to make comparison easy with Fig. 2 of Milan and Lester (1998). The lower panels display the same data in a magnetic latitude and magnetic local time (MLT) coordinate system. For reference, the pole- 
ward and equatorward edges of the statistical auroral oval for moderate geomagnetic activity are indicated in the lower panels by dot-dashed lines. Beam 0 points northeast (geomagnetic azimuth of $36^{\circ}$ ) whereas beam 15 points almost directly east ( $84^{\circ}$ azimuth), so lines of constant geomagnetic latitude and longitude, GMLAT and GMLON, curve from bottom-left to top-right and bottom-right to top-left, respectively, in the upper panels of Fig. 3. In both scans, a region of backscatter is observed equatorward of $70^{\circ}$ geomagnetic latitude (sub-divided into channels I, II, and III), which is approximately aligned along lines of constant geomagnetic latitude or, equally, the edges of the statistical auroral oval, and it is these features which are identified as E region backscatter by the interferometric measurements. Previous studies of HF radar E region backscatter, for instance, Villain et al. (1987, 1990), Milan and Lester (1998) and Milan et al. (2000), have demonstrated that such features are typically L-shell aligned and indeed, this is found to be characteristic of all E region backscatter observed during the myopic campaign. The backscatter from higher latitudes in Fig. 3 is identified as F region backscatter, whereas the sporadic or "grainy" scatter observed in the first 15 to 20 range gates (esp. at 0330 UT) is attributed to meteor scatter (Hall et al., 1997).

The sense of the line-of-sight velocities measured by the radar gives an indication of the direction of flow and hence, which electrojet is under observation. At 0330 UT (see Fig. 3) all line-of-sight velocities within the E region scatter are negative (away from the radar) which, as the radar points east of north, corresponds to an eastward flow component. This is consistent with the location of the radar in the westward electrojet region at this time. The situation is reversed at $2116 \mathrm{UT}$ when the radar is located in the eastward electrojet region. The details of the velocity observations presented in Figure 3 will be discussed more fully below. First, however, we describe the diurnal variation in the occurrence of $\mathrm{E}$ region backscatter observed during the myopic campaign, the diurnal variation in the predominant direction of flow, and also the dependence of the occurrence on geomagnetic activity. Each of the 321 hours of operation of the myopic experiment was categorised by a variety of parameters: the prevailing planetary geomagnetic disturbance index $K p$; whether a significant amount of $E$ region scatter was observed during that hour; and if so, whether the overall flow direction observed within the backscatter was consistent with the eastward or westward electrojet region. Figure 4 presents a summary of these findings. Figure 4 a shows the times of day at which the myopic experiment was conducted. The myopic mode was operated most often between 18 and $06 \mathrm{UT}$, as this is when the probability of observing E region backscatter is the greatest. In fact, the myopic observations were made on almost 20 nights between February 1998 and March 1999. Fewer measurements were made during the day; the myopic mode operating between 06 and 15 UT on only 6 days. In total, 321 hours of observations were collected. Figure $4 \mathrm{~b}$ shows the diurnal variation in the occurrence of observation of significant $\mathrm{E}$ region backscatter in each hour. The maximum in occurrence of observation occurs between 20 and 22 UT,
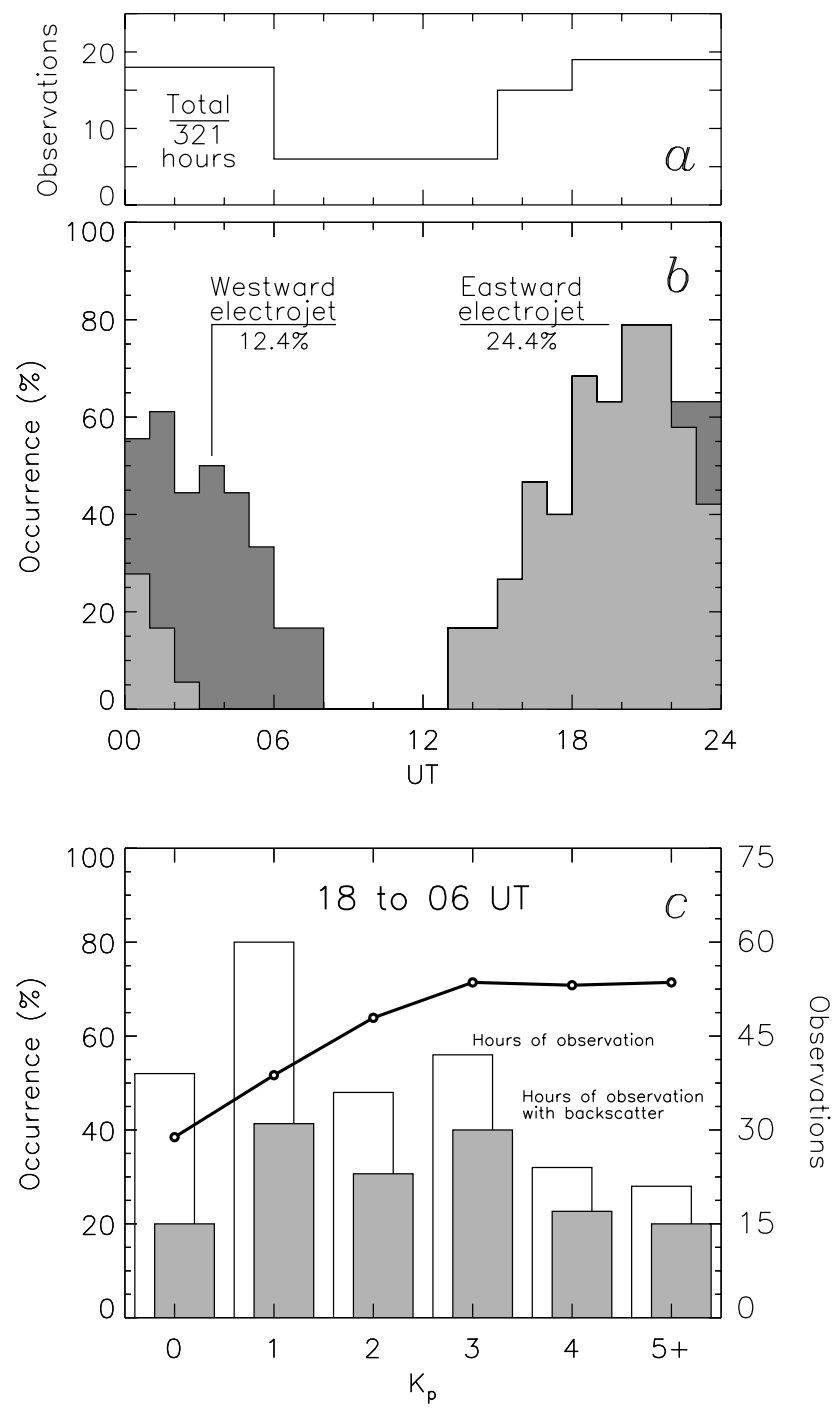

Fig. 4. (a) The diurnal coverage of the myopic campaign; of a total of 321 hours of operation, most observations were conducted between 18 and 06 UT. (b) The occurrence distribution of observation of the eastward electrojet (mainly positive velocities) and the westward electrojet (mainly negative velocities) during the myopic campaign. Local midnight occurs near 00 UT. (c) The occurrence of observation of significant electrojet backscatter, between 18 and $06 \mathrm{UT}$, as a function of the $K p$ index.

when backscatter is observed in nearly $80 \%$ of hourly bins. A dearth in backscatter occurs near local noon, though this is due in part to the auroral oval moving to high latitudes, poleward of the radar field-of-view at this time. Also indicated in Fig. $4 \mathrm{~b}$ is the proportion of backscatter in which the flows are consistent with the eastwards or westwards electrojets. The eastwards and westwards electrojets are observed primarily pre- and post-midnight, as expected. However, almost twice as much backscatter is identified as originating in the eastwards rather than the westwards electrojet. Overall, the probability of observing $\mathrm{E}$ region backscatter in any particular hour is $37 \%$; the probability of observing eastwards 

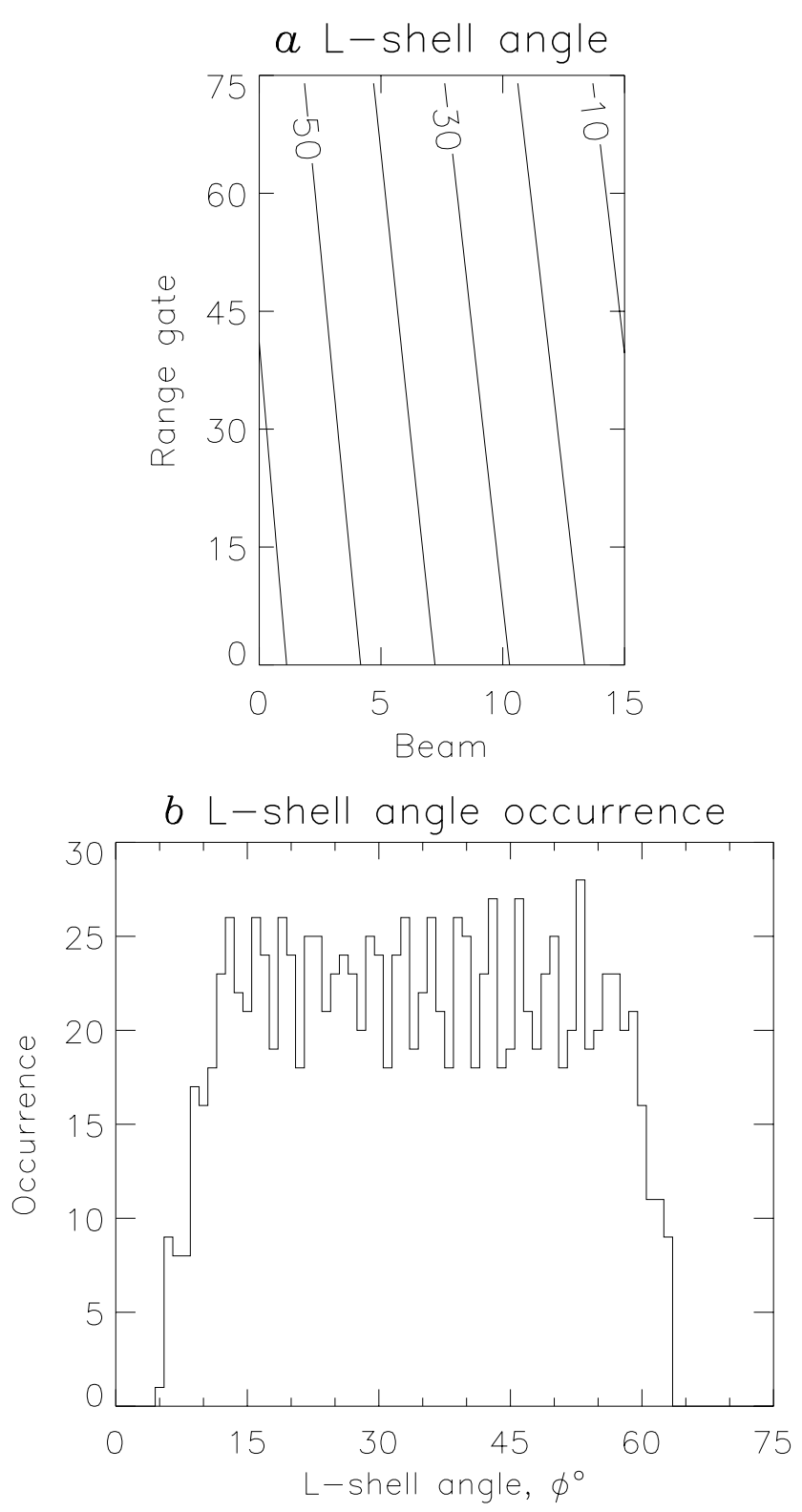

Fig. 5. (a) Contours of L-shell or flow angle within the radar fieldof-view when operating in the myopic mode. (b) The occurrence distribution, within the 1200-cell field-of-view, of different L-shell angles.

or westwards electrojet backscatter is $24 \%$ and $12 \%$, respectively. Finally, Fig. $4 \mathrm{c}$ shows the occurrence of observing backscatter in any particular hour as a function of the prevailing $K p$ conditions; these statistics were compiled solely for the hours 18 to 06 UT, when the auroral oval was well within the radar field-of-view and most backscatter was observed. Even during the quietest geomagnetic conditions, $40 \%$ of hourly bins contain backscatter. This occurrence rises with increasing $K p$, reaching a plateau of $70 \%$ for $K p$ of 3 and greater.

We now turn our attention to the spectral characteristics of
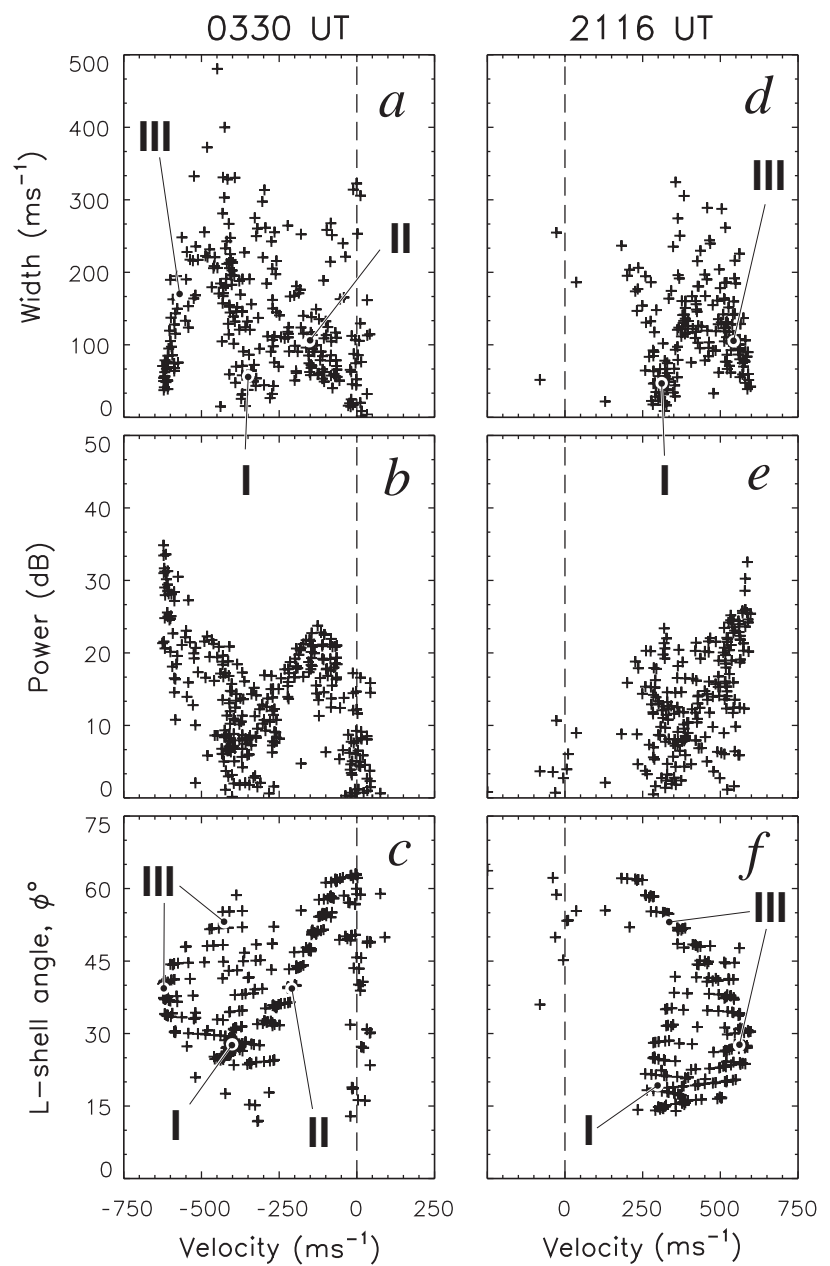

Fig. 6. The spectral characteristics of the electrojet backscatter from the radar scans presented in Fig. 3, displayed in the $\mathrm{W}-\mathrm{V}, \mathrm{P}-\mathrm{V}$, and A-V distributions.

the backscatter observed from the E region. Of most importance is the mean Doppler shift of the spectra, measured as the line-of-sight velocity. Before we can discuss the Doppler shift observations in detail, we need to define a reference frame in which the observations can be placed. In the F region, irregularities drift with the bulk plasma motion, the velocity of which, $\boldsymbol{E} \times \boldsymbol{B} / B^{2}$, is directly proportional to the convection electric field, $\boldsymbol{E}$. Radar backscatter from such irregularities has a line-of-sight Doppler shift which is proportional to $\cos \phi$, where $\phi$ is the "flow angle", the angle between the radar beam (more specifically, the irregularity wave vector $\boldsymbol{k}$ ) and the direction of plasma drift, $\phi=\cos ^{-1} \hat{\boldsymbol{k}}$. $\hat{\boldsymbol{v}}_{\boldsymbol{E} \times \boldsymbol{B}}$. It is well known from VHF radar studies, however, that in general the irregularity drift speed in the E region is not directly proportional to $\boldsymbol{E}$. However, we find it convenient to employ the concept of the flow angle in this study, as it is found to successfully order our observations. As we cannot explicitly determine the flow angle in our observations, we use instead the "L-shell angle", the angle between the beam direction and the local L-shell. We measure the 
Tranche 1
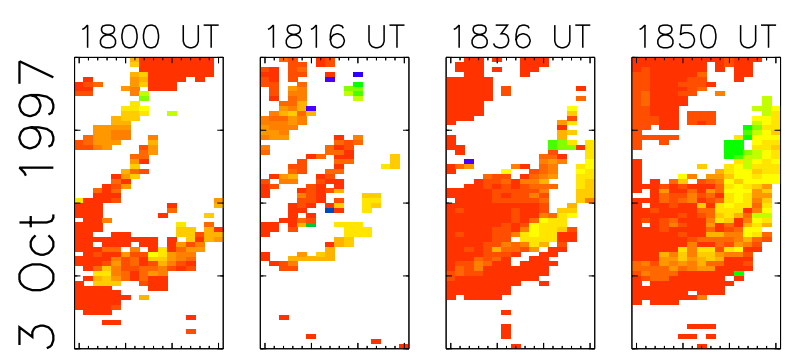

Tranche 3
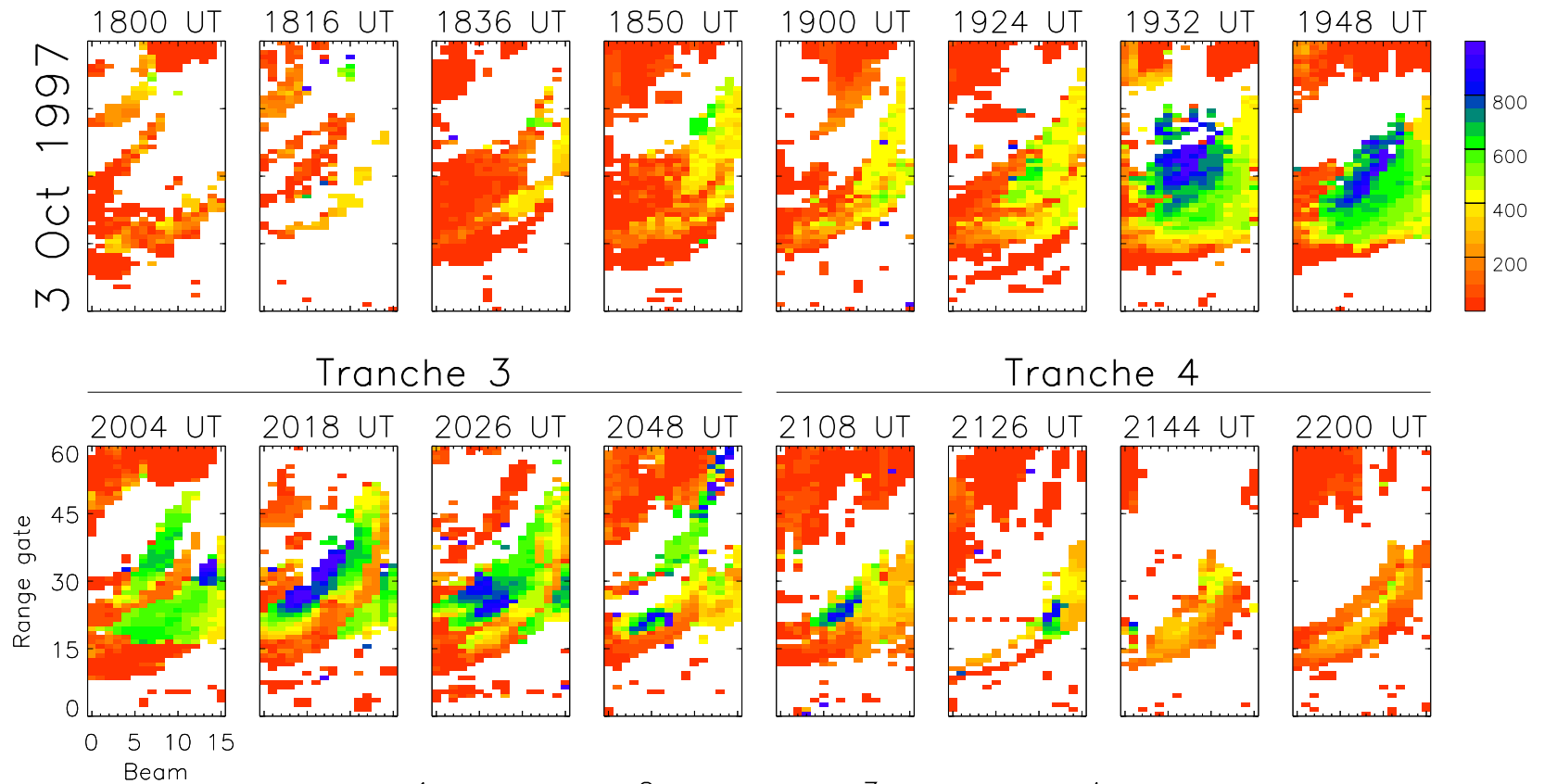

Tranche 4
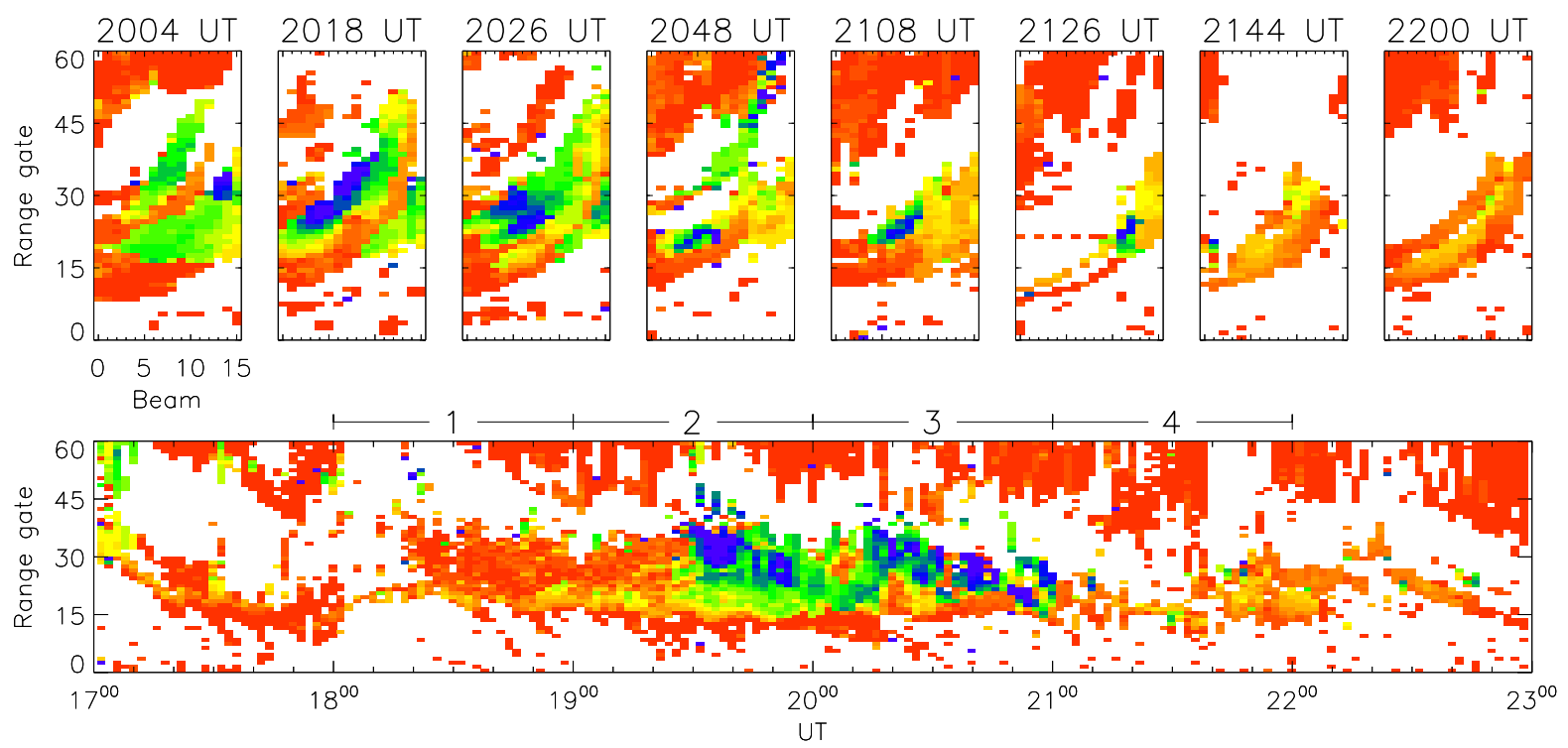

Fig. 7. (Upper panels) Radar backscatter observed between 1800 and 2200 UT, on 3 October 1997, during selected scans. (Lower panel) A range-time representation of the backscatter observed along beam 7 of the radar field-of-view between 1700 and 2300 UT.

L-shell angle anti-clockwise from east. The flow angle and the L-shell angle are equivalent if the $\boldsymbol{E} \times \boldsymbol{B}$ direction is assumed to be L-shell-aligned (a reasonable first-order approximation in the electrojet regions). Figure 5a illustrates the variation of the L-shell angle across the radar field-ofview. The highest L-shell angles (near $63^{\circ}$ ) occur in beam 0 , the most meridionally-pointing beam, and the lowest Lshell angles (near $5^{\circ}$ ) occur in beam 15 , the most zonallypointing beam. Figure $5 \mathrm{~b}$ illustrates the occurrence distribution of the L-shell angles within all 1200 cells of the field-ofview. Due to the $3.2^{\circ}$ azimuthal separation of the radar pointing directions, $\mathrm{L}$-shell angles cluster around preferred values separated by approximately $3^{\circ}$; this explains the striped appearance of some L-shell angle distributions which will be presented below. This then defines the reference frame we will employ to characterise the Doppler shift observations; Villain et al. $(1987,1990)$ found a similar strategy useful in their work. It should be noted that sampling biases exist in our observations. For instance, the portion of the radar fieldof-view in which the L-shell angle is lowest (high numbered beams) also looks to the lowest latitudes, and vice versa.
However, we do not feel that this influences our results to any great extent.

The regions of electrojet backscatter shown in Fig. 3 can be sub-divided into several L-shell-aligned channels in which the behaviour of the line-of-sight velocity is different, three in the case of 0330 UT and two in the case of 2116 UT. In the first example, the channels are observed within the approximate latitude limits $70^{\circ}-69^{\circ}, 69^{\circ}-68^{\circ}$, and $68^{\circ}-67^{\circ}$. These channels will be referred to as channels II, III, and I, respectively, for the purposes of description. In this example, channels II and III extend across the field-of-view from beam 0 to approximately beam 10 , but channel I is only observed between beams 7 and 11. In channel II, the line-of-sight velocities increase from near-zero in beam 0 to approximately $-300 \mathrm{~m} \mathrm{~s}^{-1}$ in beam 10. In this case there appears to be a relationship between line-of-sight velocity and the L-shell angle which is similar to the cosine-dependence expected for $\mathrm{F}$ region scatter. In channel III, the line-of-sight velocities are higher than in channel I. The velocity increases from near $-400 \mathrm{~m} \mathrm{~s}^{-1}$ in beam 1 to a maximum near $-600 \mathrm{~m} \mathrm{~s}^{-1}$ in beam 8 , and then decreases once again to $-400 \mathrm{~m} \mathrm{~s}^{-1}$ in 

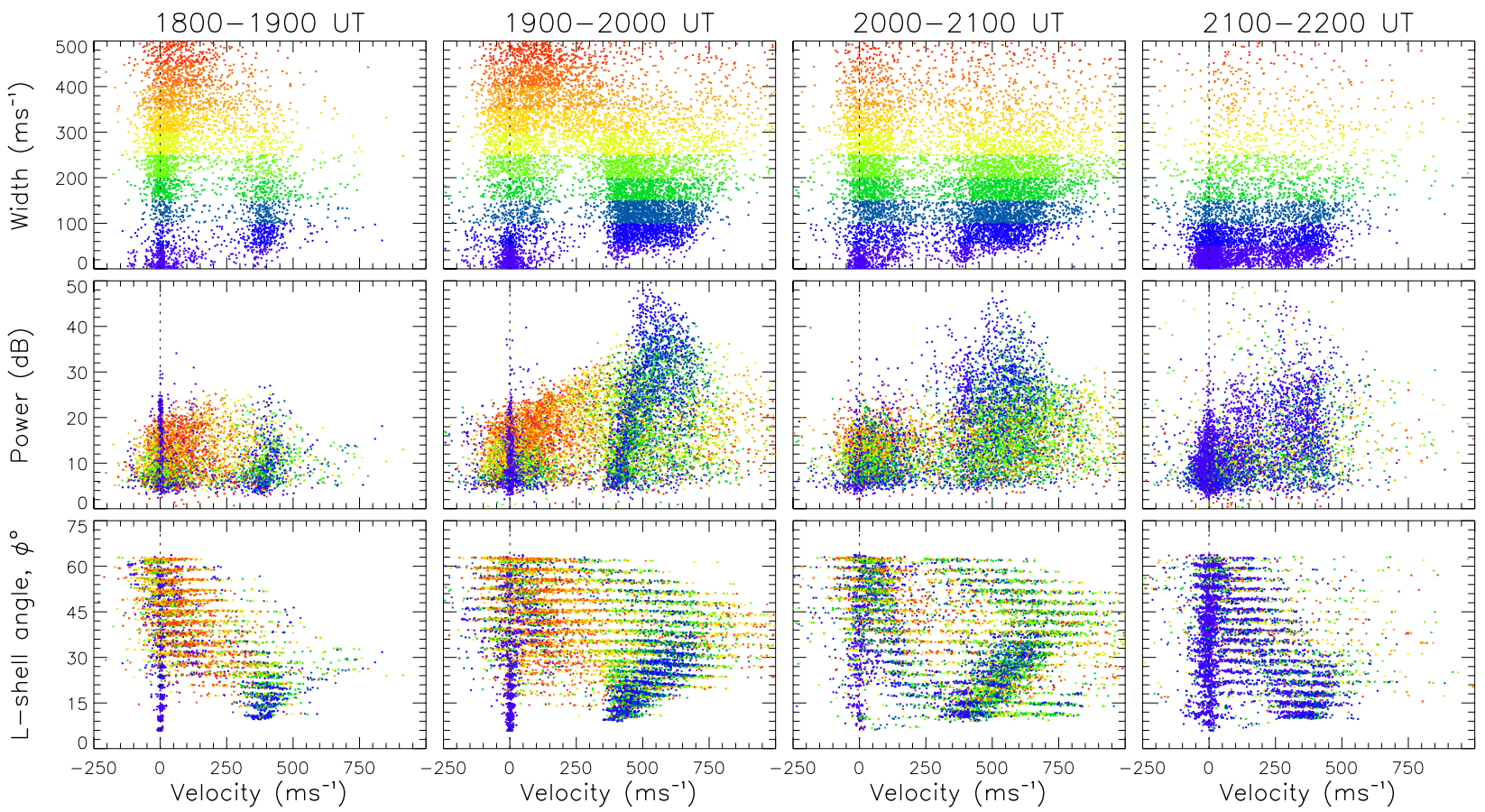

Fig. 8. Spectral characteristics from four 1-hour tranches during the interval 1800 to 2200 UT, on 3 October 1997. Points are colour-coded with spectral width, with blue being lowest and red highest.

beam 10. In other words, velocity increases with decreasing $\phi$ at high $\phi$ and decreases with decreasing $\phi$ at low $\phi$. This L-shell angle dependence is a common feature of the observations, as will be demonstrated below. Lastly, in channel I, velocities appear restricted to a narrow range between -300 $\mathrm{m} \mathrm{s}^{-1}$ and $-350 \mathrm{~m} \mathrm{~s}^{-1}$. In the second example, at $2116 \mathrm{UT}$, only two channels are observed. The pattern of velocities observed within these two channels indicate that they are the equivalent of channels I and III identified in the first example, though the line-of-sight velocities are in this case reversed.

The two examples in Fig. 3 have been selected for illustrative purposes for their relative simplicity. Much more complex interleaving of channel types can arise. This can make identification of different spectral types in the backscatter difficult. Moreover, we also need to examine the spectral width and backscatter intensity of the backscatter returns. To this end, we produce scatter plots which show the relationship between spectral width and velocity, power and velocity, and velocity and the L-shell angle of all points that are identified as E region backscatter. These will hereafter be referred to as $\mathrm{W}-\mathrm{V}, \mathrm{P}-\mathrm{V}$, and $\mathrm{A}-\mathrm{V}$ distributions. Figure 6 presents these distributions for the two scans of Fig. 3 (panels a and d, $\mathrm{b}$ and $\mathrm{e}, \mathrm{c}$ and $\mathrm{f}$ are the $\mathrm{W}-\mathrm{V}, \mathrm{P}-\mathrm{V}$ and $\mathrm{A}-\mathrm{V}$ distributions, respectively). In these we identify the spectra from channels I, II and III. At 0330 UT the spectra from channel II are clearly evident: a population that progresses from very low velocities to approximately $-250 \mathrm{~m} \mathrm{~s}^{-1}$ between the $\mathrm{L}$-shell angles of $65^{\circ}$ and $30^{\circ}$ (Fig. 6c). These spectra tend to have spectral widths between 30 and $200 \mathrm{~m} \mathrm{~s}^{-1}$ (Fig. 6a) and backscatter powers which peak at $25 \mathrm{~dB}$ (Fig. 6b). Channel I is observed in both scans, comprising a group of points clustered near $\pm 350 \mathrm{~m} \mathrm{~s}^{-1}$ and between $15^{\circ}$ and $30^{\circ}$ in the A-V distribution (Figs. 6c and f), which have narrow spectra, with spectral widths below $100 \mathrm{~m} \mathrm{~s}^{-1}$, and low backscatter powers, less than $10 \mathrm{~dB}$. Channel III is the most complex of the three. In these examples, the maximum absolute velocity observed is close to $600 \mathrm{~m} \mathrm{~s}^{-1}$, centred near an L-shell angle of $35^{\circ}$ and $25^{\circ}$ at 0330 and $2116 \mathrm{UT}$, respectively. At higher and lower L-shell angles the Doppler shift decreases. At the highest velocities the spectral widths are low, below $100 \mathrm{~m} \mathrm{~s}^{-1}$, and the backscatter powers are high, near $30 \mathrm{~dB}$. As the Doppler shift decreases, however, the spectral width increases rapidly and the backscatter power decreases rapidly.

These examples demonstrate that distinct spectral classes exist in the E region backscatter, and that these exist more or less symmetrically in the eastward and westward electrojets. We will demonstrate below that these distinct populations are observed as a matter of course in all $\mathrm{E}$ region observations and that this grouping of spectral types occurs irrespective of the complexity of the spatial structure of the electrojet backscatter. This grouping has been described previously by Milan and Lester (1999) and we draw particular attention to their Fig. 2 which shows schematically the locations of these populations in the $\mathrm{W}-\mathrm{V}, \mathrm{P}-\mathrm{V}$, and $\mathrm{A}-\mathrm{V}$ distributions. In their nomenclature the spectra of channels I and II are termed populations $i$ and $i i$, respectively; the low- $\phi$ and high- $\phi$ spectra of channel III are named populations $i i i$ and $i v$, respectively; an additional fifth population, $v$, is also indicated which we 
will discuss further below. Their diagram relates specifically to backscatter observed in the eastward electrojet; for westward electrojet backscatter, the sign of the velocities is simply reversed.

To demonstrate the ubiquity of these spectral populations, we present three further intervals of myopic observations. During the first interval, 1800 to 2200 UT on 3 October 1997, the CUTLASS Iceland radar was located in the eastward electrojet region. This interval is typical of all myopic observations, though it has been selected for illustrative purposes as the time-evolution of the spectral populations contained within the data makes their characteristics clear. Figure 7 shows a sequence of radar scans from this interval, demonstrating once again the $\mathrm{L}$-shell aligned nature of $\mathrm{E}$ region backscatter, and the interleaving of different channel-types within the backscatter. As discussed above, this interleaving can become quite complex, illustrated especially in the scans starting at 1932, 2004, and 2026 UT. Low velocity backscatter at the furthest ranges is ground backscatter. The bottom panel shows the time-evolution of the backscatter along beam 7 of the radar field-of-view. Between 1800 and 2200 UT an increase and then a subsequent decrease in the amount of $\mathrm{E}$ region backscatter is observed, though the latitudes at which the backscatter is observed do not change markedly during the interval. Furthermore, there is an increase followed by a decrease in the maximum velocity observed within this backscatter, between a minimum of $500 \mathrm{~m} \mathrm{~s}^{-1}$ and a maximum of $1000 \mathrm{~m} \mathrm{~s}^{-1}$. This period is accompanied by an increase in the $\mathrm{H}$ component of magnetograms from stations located on Iceland, indicating an enhancement of the eastward electrojet at this time. For investigation of the spectral characteristics of the backscatter, the interval has been divided into four one-hour tranches. Figure 8 presents scatter plots of the $\mathrm{W}-\mathrm{V}, \mathrm{P}-\mathrm{V}$ and $\mathrm{V}-\mathrm{A}$ distributions for the $\mathrm{E}$ region backscatter from each tranche. As can be seen most clearly in the W-V panels, each point has been colour-coded with spectral width, with blue and red corresponding to low and high spectral widths, respectively; this colour-coding is carried through into the P-V and V-A distributions as well.

In the first tranche, between 1800 and 1900 UT, two populations of spectra are observed. The first occurred with velocities near $400 \mathrm{~m} \mathrm{~s}^{-1}$, with backscatter power less than 20 $\mathrm{dB}$, and spectral width in general less than $200 \mathrm{~m} \mathrm{~s}^{-1}$. Furthermore, this population was only observed in field-of-view cells which had low L-shell angles, between $10^{\circ}$ and $30^{\circ}$. (Note that the horizontal-striped appearance of the V-A distributions is due to the L-shell angle occurrence distribution of Fig. 5.) We identify these as type I spectra backscatter from two-stream waves, which constitute the majority of the points which make up the shoulders of the E region distribution in Fig. 2. The observation that this population appears only at low L-shell angles is also apparent in the examples in Fig. 3, where channel I (type I spectra) is observed solely in high numbered beams, as presumably these correspond to look-directions which are within the two-stream "cone of instability". The second population occurs at lower velocities, has spectral widths in excess of $100 \mathrm{~m} \mathrm{~s}^{-1}$, and also has

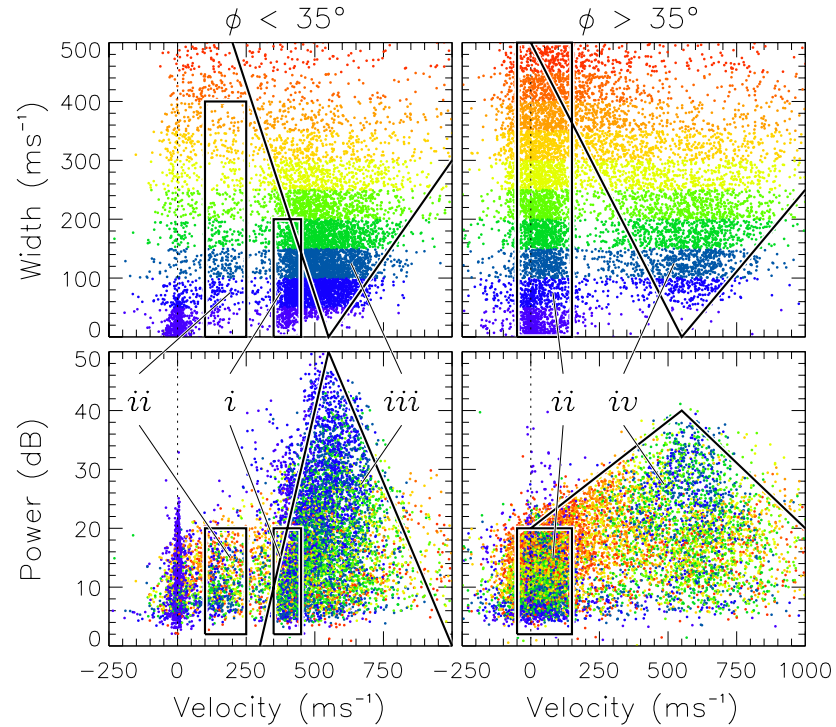

Fig. 9. Spectral characteristics during the interval 1900 to 2100 UT, on 3 October 1997, separated into L-shell angle regimes $\phi<35^{\circ}$ and $\phi>35^{\circ}$. The nomenclature of Milan and Lester (1998) is employed to distinguish the different spectral populations.

backscatter powers less that $20 \mathrm{~dB}$. This population occurs at higher L-shell angles, between $15^{\circ}$ and $60^{\circ}$, and there appears to be an increase in velocity with the decreasing L-shell angle. These are type II spectra, scatter from gradient drift irregularities, corresponding to channel II in the first example of Fig. 3.

During tranches 2 and 3, between 1900 and 2100 UT, higher velocity spectra are observed in addition to the type I and type II spectra of tranche 1. This additional population is most distinct in the A-V distribution, with the same characteristics as the channel III backscatter described above. At low L-shell angles, between $5^{\circ}$ and approximately $35^{\circ}$, Doppler shift increases with the increasing L-shell angle; at higher L-shell angles, above $35^{\circ}$, Doppler shift tends to decrease with increasing L-shell angle. In the $\mathrm{W}-\mathrm{V}$ and $\mathrm{P}-\mathrm{V}$ distributions the low- and high- $\phi$ populations are superimposed. However, spectra with Doppler shifts near $600 \mathrm{~m} \mathrm{~s}^{-1}$ tend to be of the highest backscatter power and the lowest spectral width. It is interesting to note that in the A-V and P-V distributions this high Doppler shift, low spectral width population appears to grow out of the pre-existing channel I population at a velocity near $350 \mathrm{~m} \mathrm{~s}^{-1}$, low $\phi$ and low backscatter power. This is also evident in Fig. 6 in which the channel I spectra appear near the low- $\phi$ end of the channel III population in the $\mathrm{A}-\mathrm{V}$ distribution. This close association between the channel I and channel III populations perhaps suggests that the latter is brought about due to a modification of the two-stream dispersion relationship, as will be discussed later. To aid the distinction between the low- and high- $\phi$ populations of channel III, Fig. 9 displays the W-V and PV distributions for the period 1900 to 2100 UT, separated into the L-shell angle regimes $\phi<35^{\circ}$ and $\phi>35^{\circ}$. The 

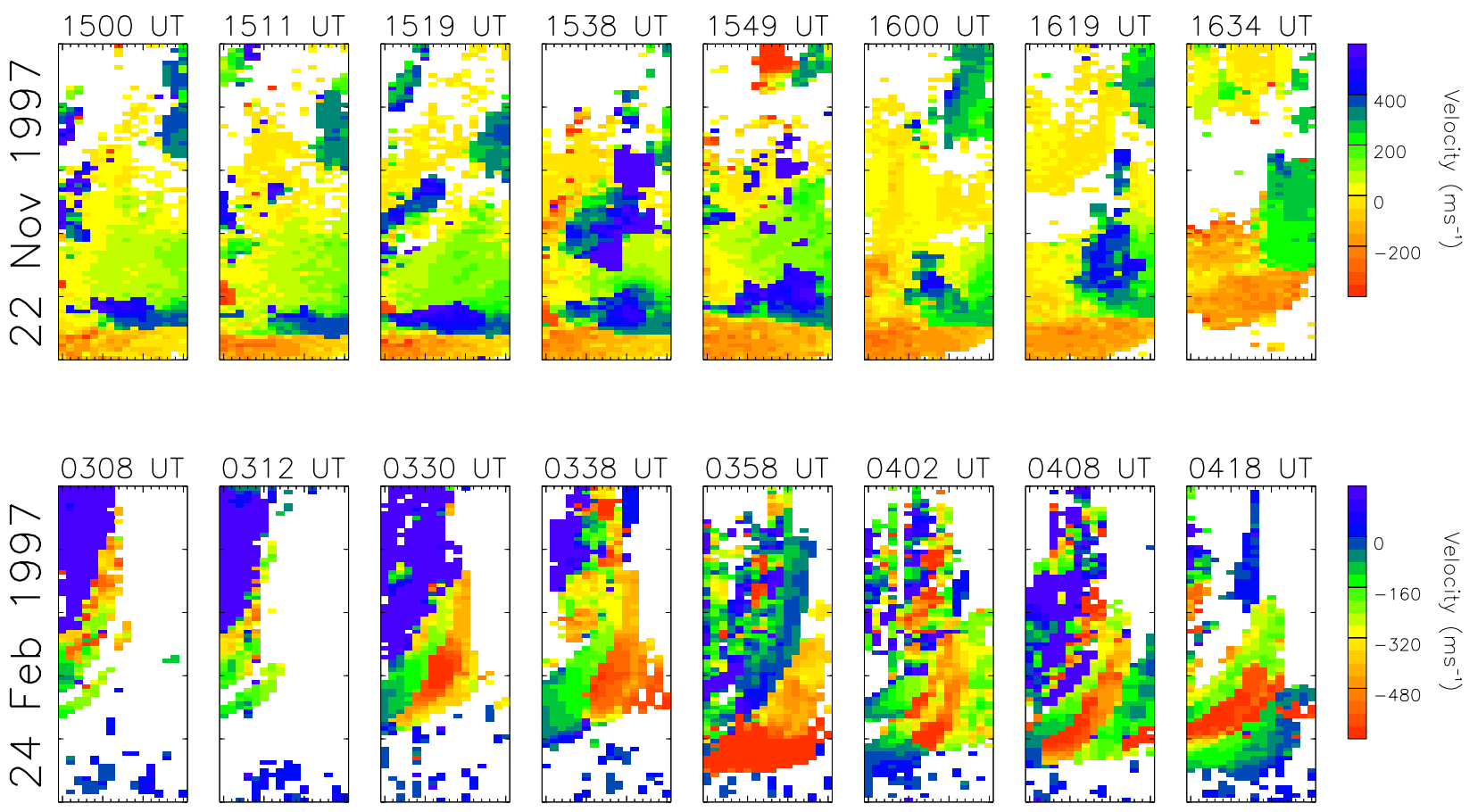

Fig. 10. (Upper panels) Radar backscatter observed between 1500 and 1634 UT, on 22 November 1997, during selected scans. (Lower panels) Radar backscatter observed between 0308 and 0418 UT, on 24 February 1997, during selected scans.

approximate edges of the populations have been overlaid as solid lines, following the classification scheme of Milan and Lester (1999): populations $i$ and $i i$ correspond to channels I and II, and populations $i i i$ and $i v$ to the low- and high- $\phi$ portions of channel III, respectively. Population iii tends to be of lower spectral width and has higher peak backscatter powers than population $i v$. However, population iii is predominantly observed only between Doppler shifts of 350 and $900 \mathrm{~m} \mathrm{~s}^{-1}$, whereas population iii is observed between 0 and $900 \mathrm{~m} \mathrm{~s}^{-1}$. In other words, population iii is only observed with Doppler shifts greater than the nominal ion acoustic speed.

After 2100 UT the high Doppler shift spectra are no longer observed, and the observed distributions return to a situation similar to the 1800 UT to 1900 UT tranche (Fig. 8). On the whole, narrow spectra appear to dominate the distributions.

The time evolution observed throughout the whole of the interval indicates that spectral populations come and go, presumably in response to changes in the magnitude of the electrojet strength and maybe variations in the electron density distribution within the E region. However, when a population appears, it tends to follow a characteristic pattern in the W-V, P-V, and V-A distributions. This can be emphasised by studying the reproducibility of these spectral distributions during other myopic runs. The last two intervals we describe briefly show this reproducibility. In addition, the first of these will introduce one further spectral population to those already discussed. Figure 10 shows a selection of radar scans from these two intervals, the top panels from 22 November 1997 and the bottom panels from 24 February
1997. The spectral characteristics of these two intervals are presented in Fig. 11. In the first example, a broad region of electrojet backscatter is observed which fills the near-range field-of-view of the radar. As time progresses, however, the electrojet progresses to higher ranges and the $\mathrm{L}$ - shell aligned nature of the backscatter becomes apparent, especially after 1600 UT. The channels we are now familiar with are not so easily discernible within the backscatter as in previous examples. However, the spectral characteristics from the interval (Fig. 11) display the populations associated with channeltypes II and III. A very interesting additional population is also observed. Most Doppler shifts within the backscatter are positive, as the radar is located in the eastward electrojet at this time. However, at the very closest ranges, the first 6 to 10 gates of backscatter or so, negative Doppler shifts are observed. This is the last class of spectra observed in myopic data, which was termed population $v$ by Milan and Lester (1999). The demarcation between negative and positive Doppler shifts in Fig. 10 is very sharp and appears to occur at a specific radar range rather than being an L-shell aligned boundary, as most features in electrojet backscatter are. This characteristic feature is most apparent in the scan from 1619 UT in which the edges of the electrojet feature are L-shell aligned, but the boundary between population $v$ and the rest of the electrojet backscatter occurs at range gate 10 . Figure 11 indicates that these negative Doppler spectra display an L-shell angle dependence, as velocity increases with increasing $\phi$. In addition, these spectra are broad, having spectral widths in excess of $200 \mathrm{~m} \mathrm{~s}^{-1}$. One further popu- 

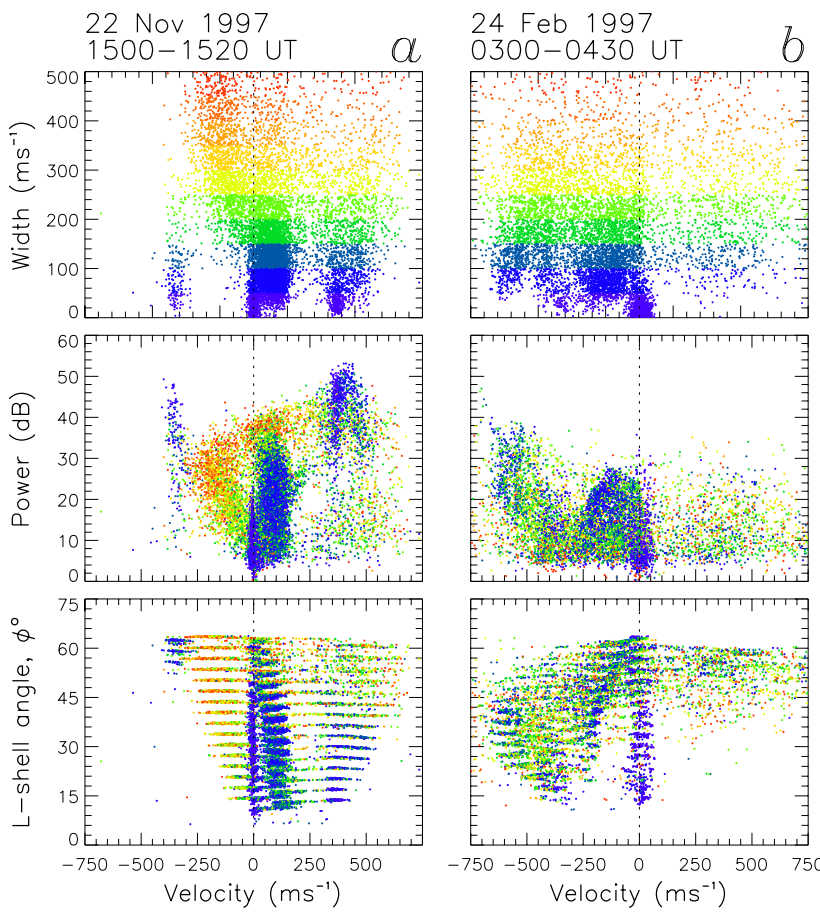

Fig. 11. Spectral characteristics from the two intervals presented in Fig. 10. Points are colour-coded with spectral width, blue being lowest and red highest.

lation is seen near $-350 \mathrm{~m} \mathrm{~s}^{-1}$ Doppler shift with narrow spectral widths. This population is an instrumental artefact, however, with backscatter observed behind the radar (see Milan et al., 1997).

In the final example on 24 February 1997, the L-shell aligned nature of the backscatter is again apparent. The radar is within the westward electrojet at this time and hence, the Doppler shifts are predominantly negative in this case. Once again, channel I, II, and III-type spectra are present in the backscatter.

As a less-detailed overview of the myopic dataset, Figs. 12 and 13 present $\mathrm{A}-\mathrm{V}$ occurrence distributions from 16 intervals, 8 from the westward electrojet and 8 from the eastward electrojet, respectively. These distributions are colourcoded on an arbitrary scale, which is different in each example, to represent occurrence, black being zero occurrence and red being greatest occurrence, in each bin $20 \mathrm{~m} \mathrm{~s}^{-1}$ wide in velocity by $1^{\circ}$ in the L-shell angle. In each of these, one or more of the spectral populations described above can be identified. In general, low Doppler-shift spectra dominate the occurrence plots; channel I and II-type spectra are the most populous. Also, low- $\phi$ channel III spectra dominate in numbers over high- $\phi$ spectra. However, high- $\phi$ are still much in evidence, especially in the eastward electrojet observations. These figures also demonstrate that while each of the spectral populations are relatively ubiquitous, their exact locations within the V-A distribution vary from example to example. For instance, the maximum velocity within the channel III populations, and the L-shell angle in which this maximum occurs, differ slightly from day to day.

\section{Discussion}

High spatial resolution HF radar observations of backscatter from the auroral $\mathrm{E}$ region indicate that five spectral populations are commonly observed, with distinctive spectral width, Doppler shift and backscatter power distributions. These populations are as follows: 1) Narrow spectra with a mean Doppler shift near the ambient value of the ion-acoustic speed; these appear similar to type I spectra observed at VHF frequencies. 2) Broader spectra with Doppler shifts below the ion-acoustic speed, similar to VHF type II spectra. These Doppler shifts increase with the decreasing L-shell angle, as would be expected if the Doppler shift were the line-ofsight component of the $\boldsymbol{E} \times \boldsymbol{B}$ drift. 3) Spectra with Doppler shifts greater than the ambient ion-acoustic speed, which appear at low L-shell angles, and whose Doppler shift increases with the increasing L-shell angle. 4) Spectra whose Doppler shift is generally greater than the ambient ion-acoustic speed, which appear at the high L-shell angles, with Doppler shifts which decrease with the increasing L-shell angle. 5) Broad spectra whose Doppler shifts are of opposite sign to that of other spectra in the electrojet backscatter. These Doppler shifts are lower than the ambient ion-acoustic speed. These spectra appear only in the nearest ranges of the field-of-view, and the demarcation between this region of backscatter and other spectral types is dependent on range and is not L-shell aligned. Milan and Lester (1999) termed these spectral types populations $i$ to $v$, respectively. These spectral populations are thought to be characteristic of the irregularity types and instability mechanisms operating in the $\mathrm{E}$ and upper-E regions, and are not necessarily a consequence of large-scale features in the flow pattern. The different populations are then produced by the plasma dynamics within each radar cell and depend on the orientation of the look-direction of the radar with respect to $\boldsymbol{E}$ (to close approximation, the L-shell angle) and possibly electron density gradients as will be discussed below.

These results contrast with observations in the VHF regime, i.e. at irregularity wavelengths near 1 to $3 \mathrm{~m}$ (as opposed to $15 \mathrm{~m}$ ), where two main spectral populations are observed, type I and type II, generated by the two-stream and gradient drift instabilities, respectively (Haldoupis, 1989). Type I spectra have Doppler shifts close to the ambient ionacoustic speed and type II spectra have Doppler shifts below this. However, it perhaps should come as no surprise that more spectral types are observed at HF frequencies than previously at VHF frequencies. Even within the VHF regime a wavelength dependence is suggested by the fact that most observations of the exotic spectral types III and IV occur at $50 \mathrm{MHz}$ as opposed to $150 \mathrm{MHz}$ (Haldoupis, 1989). Type III spectra are thought to be scatter from electrostatic ion cyclotron, or EIC waves in the upper E region, whereas type IV spectra, with Doppler shifts exceeding the ambient ion- 

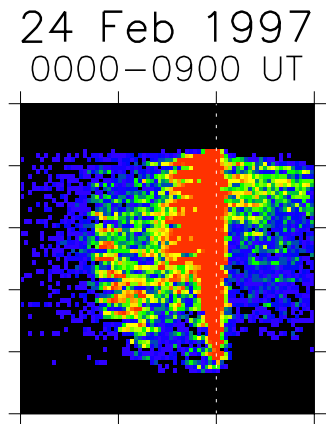

10 Oct 1997 0000-0600 UT

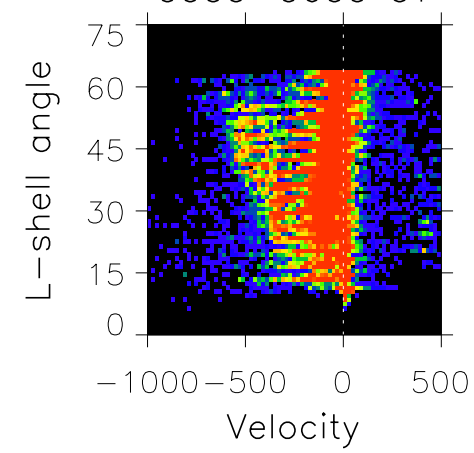

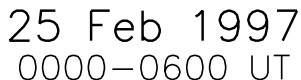

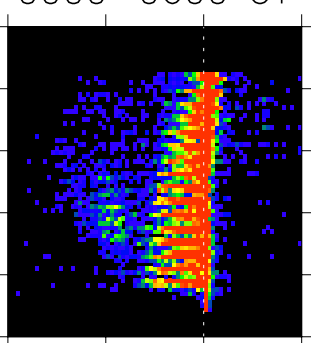

21 Nov 1997 0100-0200 UT

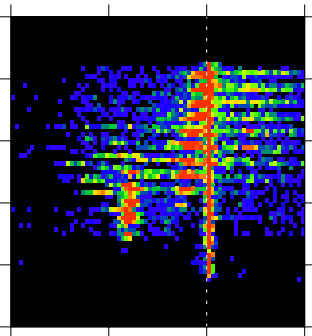

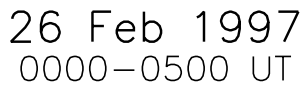

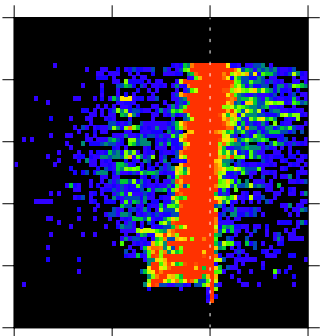

23 Nov 1997 $1700-2400$ UT

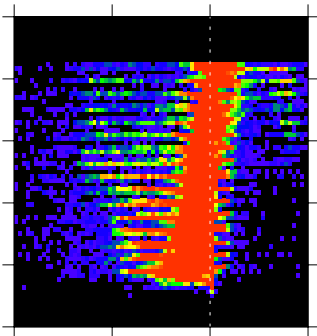

09 Oct 1997 0000-0600 UT

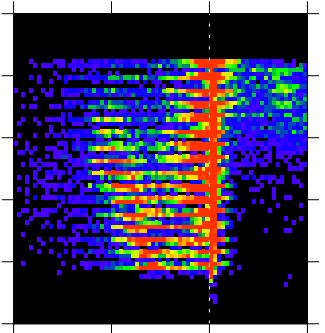

09 Mar 1998 2300-0200 UT

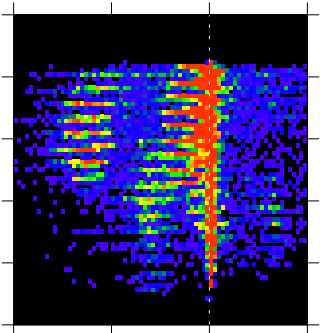

Fig. 12. Spectral characteristics, displayed as occurrence distributions (red represents the highest occurrence, black represents no occurrence) for 8 intervals of myopic observations in the westwards electrojet.
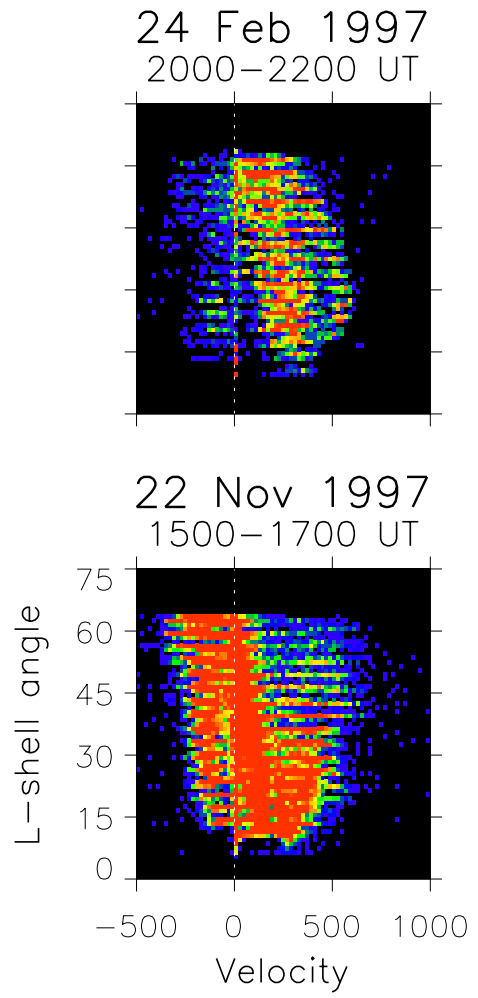
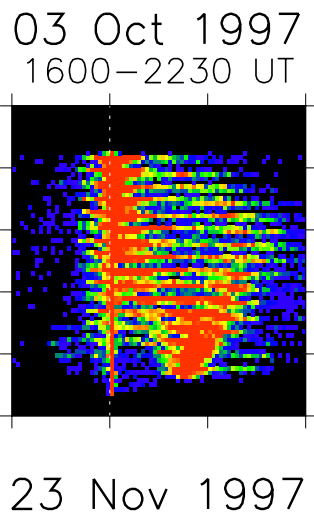

$1630-2230$ UT

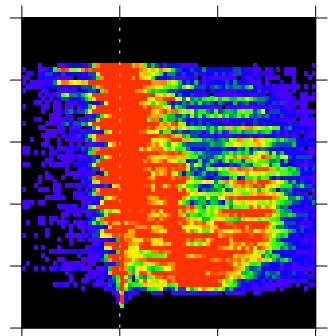

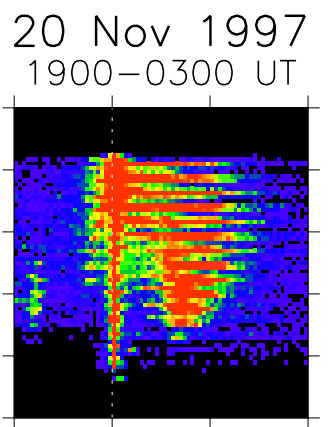

14 Feb 1998 $1700-2400$ UT

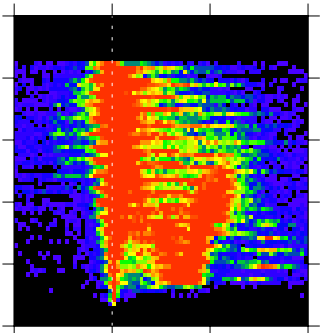

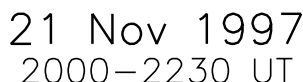

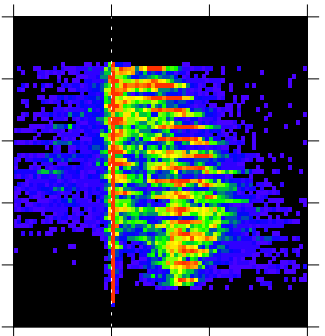

30 Mar 1998 $1800-2200$ UT

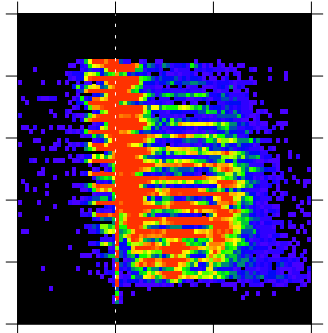

Fig. 13. Spectral characteristics, displayed as occurrence distributions (red represents the highest occurrence, black represents no occurrence) for 8 intervals of myopic observations in the eastwards electrojet. 
acoustic speed, are thought to occur in regions of the ionosphere in which the local value of $C_{s}$ has been enhanced through heating effects (Robinson, 1986). Observation at HF frequencies represents a move to even longer irregularity wavelengths, and perhaps the occurrence of type III and type IV spectra should be expected to increase. Indeed, Villain et al. $(1987$; 1990) reported HF radar observations of spectra which appeared consistent with generation by the $\mathrm{NO}^{+} \mathrm{EIC}$ instability, i.e. the HF equivalent of VHF type III spectra. In these studies, regions of high Doppler shift echoes superimposed on a slower-moving background were interpreted as two-stream $\left(\omega_{k}=k C_{s}\right)$ and EIC $\left(\omega_{k}^{2}=\Omega_{i}^{2}+k^{2} C_{s}^{2}\right)$ waves occurring in regions of sub-critical field-perpendicular electron drifts $\left(V_{\perp}<\omega_{k} / k\right)$; here $\omega_{k}$ is the irregularity wave frequency, $k$ is the wave number, and $\Omega_{i}$ is the ion gyrofrequency. By sub-critical we mean that the field-perpendicular electric field is less than the threshold necessary for the generation of these waves. Chaturvedi et al. (1987) predicted that such waves could be generated, despite sub-critical electric field, if significant field-parallel electron drifts (fieldaligned currents) were present. However, the observations of Villain et al. bear a striking resemblance to those of the present study (cf. channel III in our Fig. 3 with Plate 3 of Villain et al. (1987)). The L-shell angle dependence found for our channel III spectra does not appear consistent with the known characteristics of the EIC instability, for which the Doppler shift is predicted to be

$V=\frac{\omega_{k}}{k}=\sqrt{\frac{\Omega_{i}^{2}}{k^{2}}+C_{s}^{2}}$

independent of look-direction. As mentioned above, heating effects can elevate the ion-acoustic speed generating type IV spectra with Doppler shifts greater than $400 \mathrm{~m} \mathrm{~s}^{-1}$. However, while such a mechanism could also be active in the case of the present observations, this again cannot explain the dependence of the Doppler shift on radar look-direction. Another way to produce waves with velocities above or below the ion-acoustic speed is to introduce electron density gradients, as described by the modified two-stream theory (Rogister and D'Angelo, 1970; Sudan et al., 1973; Fejer et al., 1975, 1984). Here the presence of an electron density gradient can stabilise or destabilise the $\mathrm{E}$ region to the generation of two-stream waves, requiring that a larger or smaller electric field is necessary to trigger the generation of irregularities and hence, backscatter. St-Maurice et al. (1994) reinterpreted the observations of Villain et al. (1987) in terms of this idea, suggesting that the high Doppler shift spectra were generated not by EIC waves but by two-stream waves in the presence of stabilising electron density gradients. To investigate this further we present the modified two-stream dispersion relationship as formulated by Hamza and St-Maurice (1993) who included the effects of turbulent mode-coupling processes on the Doppler broadening of E region spectra as well as the effect of electron density gradients. In this framework the zero growth rate condition is given by the following relation between the spectral mean frequency shift, $\bar{\omega}_{k}$, and the spectral width, $\Delta \omega_{k}$ :

$$
\begin{gathered}
\frac{\Psi}{v_{i}(1+\Psi)}\left(\bar{\omega}_{k}^{2}+\Delta \omega_{k}^{2}-k_{\perp}^{2} C_{s}^{2}\right) \\
+\frac{\boldsymbol{k} \cdot \boldsymbol{K}}{k^{2}(1+\Psi)} \frac{v_{i}}{\Omega_{i}} \bar{\omega}_{k}=0
\end{gathered}
$$

where $\boldsymbol{K}=\nabla N_{0} / N_{0} \times \hat{\boldsymbol{B}}$ defines the electron density gradient perpendicular to the magnetic field $\boldsymbol{B}$ (with a scale length $L=1 / K), \Psi=v_{e} v_{i} /\left(\Omega_{e} \Omega_{i}\right)$ for field-aligned irregularities, and $v_{n}$ and $\Omega_{n}$ are the electron and ion collision frequencies and gyrofrequencies. Initially we set the Doppler broadening term $\Delta \omega_{k}$ to zero to investigate solely the effects of electron density gradients on the backscatter characteristics. In this context, the $\boldsymbol{k} \cdot \boldsymbol{K} / k^{2}$ term of (3) is of interest. The $k^{-1} \mathrm{de}-$ pendence of this term indicates that gradients play a more significant role in influencing the dispersion relationship at longer wavelengths, i.e. at HF frequencies as opposed to VHF frequencies, as argued by St-Maurice et al. (1994). We can reformulate (3) in terms of Doppler velocity $V\left(=\bar{\omega}_{k} / k\right)$ :

$\frac{\Psi}{v_{i}(1+\Psi)}\left(V^{2}-C_{s}^{2}\right)+\frac{V \cos \theta}{k^{2} L(1+\Psi)} \frac{v_{i}}{\Omega_{i}}=0$,

where $\theta$ is the angle between $\boldsymbol{K}$ defining the electron density direction and the irregularity wave vector $\boldsymbol{k}$. The irregularity characteristics are now determined by the direction of irregularity wave propagation with respect to the dominant electron density gradients. If these gradients have preferred orientations in the electrojet regions, then this defines a reference frame which could produce the L-shell angle dependence in backscatter characteristics observed in the present study. To model this L-shell angle dependence we assume that the electrojet electron drift $\boldsymbol{V}_{e}$ is directed westwards along the local L-shell (eastwards electrojet) and hence $\boldsymbol{E}$ is directed polewards. The magnetic field is taken to be pointing directly downwards. The angle between the radar look-direction and the direction of electron drift is $180^{\circ}+\phi$, where $\phi$ is the radar look-direction in terms of L-shell angle (measured anticlockwise from east). The line-of-sight component of the electron drift is given by $V_{\text {los }}=-V_{e} \cos (180+\phi)$, where this is made negative as SuperDARN velocities are conventionally positive towards the radar. Similarly, the azimuth of the irregularity wave vector $\boldsymbol{k}$ is $180^{\circ}+\phi$ as this is scattered back along the radar look-direction. A good correspondence between our model and the observations is found if we also assume that $\boldsymbol{K}$ is directed polewards, so now the angle between $\boldsymbol{k}$ and $\boldsymbol{K}$ is $\theta=90^{\circ}+\phi$. Finally, we choose the values of $V_{e}=800$ $\mathrm{m} \mathrm{s}^{-1}, C_{s}=400 \mathrm{~m} \mathrm{~s}^{-1}$, and use typical $\mathrm{E}$ region values of the collision- and gyrofrequencies. Figure 14 presents the irregularity growth rate $\Gamma$ of the modified two-stream instability as a function of irregularity drift speed (Doppler shift) and radar look direction $\phi$ for three cases, where $L=\infty$ (essentially no electron density gradient) and $L= \pm 10 \mathrm{~km}$. The contours are on an arbitary scale, though the thick contour shows the $\Gamma=0$ condition given by Eq. (4), and the shaded region indicates where $\Gamma>0$. The dotted line shows 

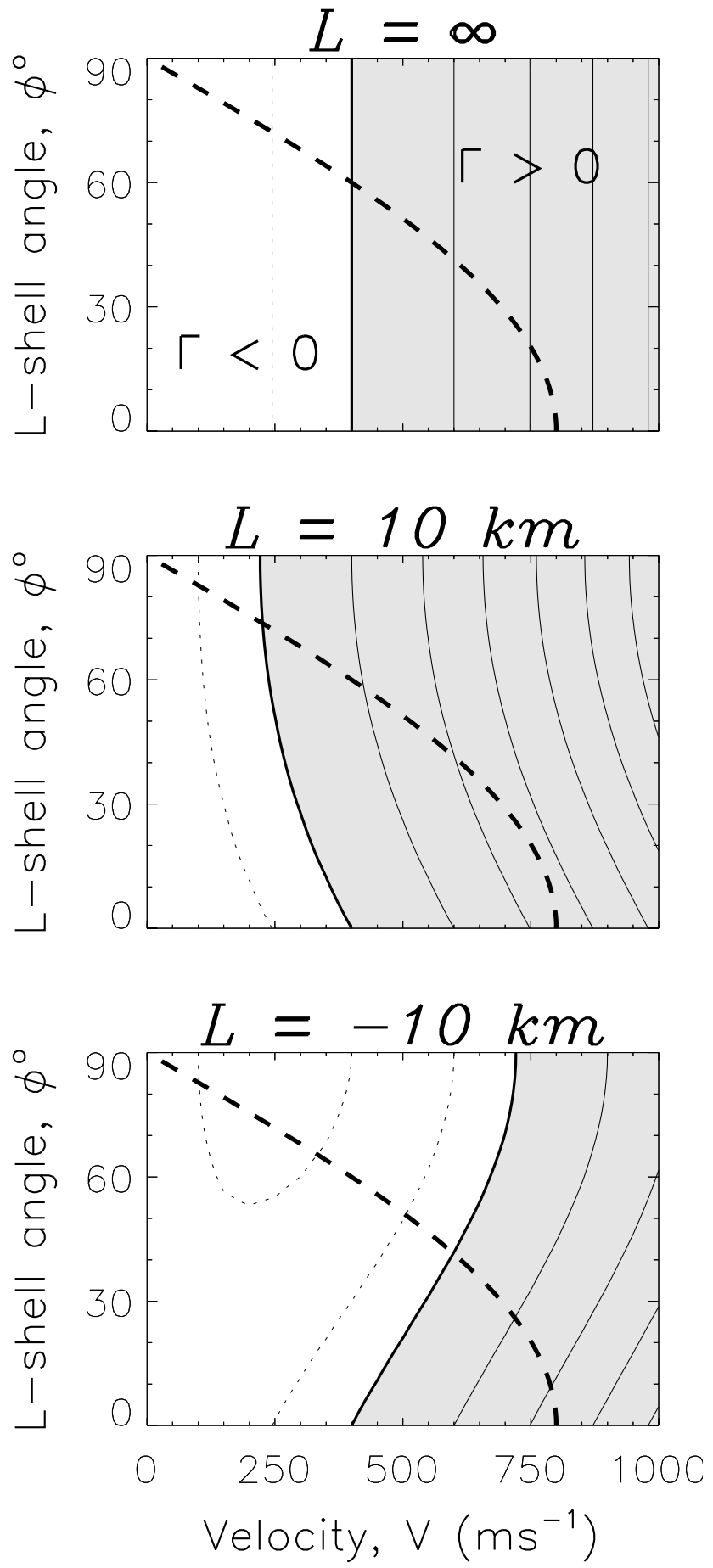

Fig. 14. Model growth rates for the stabilised and destabilised modified two-stream instability. See text for details.

the line-of-sight component of the electron drift as a function of $\phi$. In the theory of Hamza and St-Maurice (1993), if the line-of-sight drift exceeds the Doppler shift at which the $\Gamma=0$ condition is met, $V(\Gamma=0)$, then two-stream waves are generated which drift at this threshold velocity. Below this threshold, gradient drift waves are excited if a signifi- cant electron density gradient is present, which drift with the line-of-sight component of the electron drift. In the first case presented, as no gradients are present, the threshold velocity $V(\Gamma=0)$ is independent of look-direction and is everywhere equal to $C_{s}$. $V_{\text {los }}$ exceeds $V(\Gamma=0)$ for $\phi<60^{\circ}$ and so here, within the "cone of instability", two-stream waves are observed. Outside of this, no gradient drift waves are expected as no gradient is present. This is the equivalent of our channel I spectra. In the second case, where $L \approx 10 \mathrm{~km}$, the electron density gradient destabilises the two-stream instability and the threshold velocity is decreased. The maximum effect is observed at $\phi=90^{\circ}$ where the effective gradient scale length $L_{\text {eff }}=L$. At lower $\phi$ the effective scale length is given by $L_{\mathrm{eff}}=b L /|\cos \theta|=L /\left|\cos \left(90^{\circ}+\phi\right)\right|$ and $V(\Gamma=0)$ tends towards $C_{s}$. In this example, $V_{\operatorname{los}}>V(\Gamma=0)$ for $\phi<75^{\circ}$ and two-stream waves are observed with Doppler shifts below $C_{s}$ but which increase with the decreasing L-shell angle. This appears closely related to our channel II spectral population. At $\phi>75^{\circ}$ gradient drift waves will be excited in the ambient electron density gradient, but these are not observed in our experiment as the L-shell angles this high are not sampled. In the final example, the electron density gradient points in the opposite direction and has a stabilising effect on the two-stream instability. In general, velocities in excess of $C_{s}$ must be attained before two-stream waves are generated. In a similar manner to before, though, the stabilising effect is greatest at high $\phi$, and so it is only for $\phi<40^{\circ}$ that the threshold velocity is exceeded and two-stream waves are observed. In this regime, the variation in $L_{\text {eff }}$ with $\phi$ means that the backscatter Doppler shift increases with the increasing Lshell angle. In look-directions where the two-stream waves are not excited, gradient drift waves are observed which have Doppler shifts equal to $V_{\mathrm{los}}$, in other words, which decrease with the increasing L-shell angle. This is highly reminiscent of the characteristics of the channel III spectra. In this way, the characteristics of the major spectral populations observed in E region backscatter can be explained solely in terms of variations in electron density gradients; in this case, the electric field is constant everywhere, as is the ion- acoustic speed. One important repercussion of this idea is that channel II spectra, thought previously to be backscatter from gradient drift waves, could be re- interpreted as destabilised two-stream waves. If it was assumed that the Doppler shift of these spectra was equal to the line-of-sight component of the electron drift, as would be the case for gradient drift waves, then the electric field would be significantly underestimated. Our model has one major flaw. We have assumed that $\boldsymbol{K}$ is directed meridionally, which requires that $\nabla N_{0}$ is directed eastwards or westwards. We do not expect that this is routinely the case in the electrojet regions. Indeed, the L-shell aligned nature of discrete auroral forms and ionosonde observations (Whalen, 1983) would suggest that $\nabla N_{0}$ itself is more likely to be directed meridionally, and hence, $\boldsymbol{K}$ would point zonally. Potentially, a geometry other than that which we have modelled is responsible for the spectral characteristics we observe. However, we have demonstrated that electron density gradients could play a significant role in shaping 
the spectral populations observed in E region backscatter.

Turning to the Doppler broadening of the spectra, the inclusion of the $\Delta \omega_{k}$ term in Eq. (3) means that, in the absence of horizontal electron density gradients $(K=0), \bar{\omega}_{k}^{2}+$ $\Delta \omega_{k}^{2}=k^{2} C_{s}^{2}$ and not $\bar{\omega}_{k}=k C_{s}$, as predicted by previous theories. Hence, a relationship can exist between the Doppler shift and the spectral width of two-stream waves. In theory, the mean Doppler shift of backscatter spectra can drop below the ion-acoustic speed if the spectra become broad. This can be taken to the limit where low Doppler shift spectra, if generated by the two stream irregularities, should have spectral widths close to the ion- acoustic speed (St-Maurice et al., 1994). Some evidence for such a relationship possibly exists in the present data set: as noted in the discussion of the W-V distributions of Figs. 6a and d, as the Doppler shift of channel III spectra decreases, the spectral width tends to increase. Such a relationship has previously been demonstrated in HF radar E region backscatter by Eglitis and Robinson (1998).

In a final point, we discuss the possible conditions under which population $v$ spectra are observed, those spectra which appear to have a Doppler shift of opposite sense to all other backscatter in the electrojet region. Milan and Lester (1998) noted an association between E region backscatter and ground backscatter observed at twice the range, suggesting that $\mathrm{E}$ region backscatter features appear to be associated with enhancements of the E region electron density. Such enhancements lead to significant refraction of the radar signal, allowing the orthogonality condition to be achieved, which is necessary to observe backscatter from field-aligned irregularities. As the magnetic field is aligned essentially vertically, only a little more refraction of the radar beam is necessary before it is reflected back towards the ground, resulting in ground backscatter often being observed at twice the range of the ionospheric backscatter. Indeed, if the radar beam is reflected to the ground, the orthogonality condition is necessarily met at some point on the ray trajectory. One important consequence of this is that scatter can only be observed from altitudes below the $\mathrm{E}$ region peak. The minimum range at which reflection can occur (and hence, the minimum range at which ground backscatter is observed, known as the "skip distance") is dependent only on the radar operating frequency and the maximum electron density in the E region, and not on the radar look-direction. E region scatter which is observed closer than this minimum range occurs on rays which are not reflected in the $\mathrm{E}$ region, and which penetrate the $\mathrm{E}$ region peak, and which do not meet the orthogonality condition. It is possible, then, that population $v$ is high aspect angle scatter from the topside E region, and indeed, there is interferometric and ray-tracing evidence to support this scenario. Unfortunately, a detailed discussion of this is beyond the scope of the present paper, though this will be the subject of a forthcoming study.

\section{Conclusions}

The spectral characteristics of HF radar backscatter from the E region are more complex than those observed by VHF radars. In addition to the two main spectral populations observed at metre wavelengths, types I and II, in the decametrewavelength regime three other populations have been identified. These populations can have velocities which greatly exceed the expected value of the ion acoustic speed, or have a Doppler shift of opposite sign to that expected for the direction of $\boldsymbol{E}$. It is possible that electron density gradients are more significant at HF than at VHF in enhancing or depressing the threshold velocity for marginal growth of the twostream irregularities with respect to the ambient ion-acoustic speed. It is also suggested that the threshold velocity for growth of these irregularities is critically dependent on the orientation of the electron density gradients with respect to the radar look-direction, introducing variations in observed spectral characteristics with flow angle. Further investigation of these observations should help elucidate the instability processes occurring in the ionospheric $\mathrm{E}$ region. Future work will involve determination of the frequency dependence of the nature of the backscatter: exploiting the $8 \mathrm{MHz}$ to 20 $\mathrm{MHz}$ frequency agility of the SuperDARN radars will allow $k$ to be varied by a factor of 2 . In addition, a more detailed investigation of the altitude of occurrence of the different spectral populations will be undertaken.

Acknowledgements. CUTLASS is supported by the Particle Physics and Astronomy Research Council (PPARC grant no. PPA/R/R/1997/ 00256), UK, the Swedish Institute for Space Physics, Uppsala, and the Finnish Meteorological Institute, Helsinki. SEM is supported on PPARC grant no. PPA/G/O/1997/000254.

The Editor-in-Chief thanks P. Eglitis and J. C. Cerisier for their help in evaluating their paper.

\section{References}

Buneman, O., Excitation of field aligned sound waves by electron streams, Phys. Rev. Lett., 10, 285-287, 1963.

Chaturvedi, P. K., Huba, J. D., Ossakow, S. L., Saryanarayana, P., and Fedder, J. A., Parallel current effects on two-stream electrojet plasma instabilities, J. Geophys. Res., 92, 8700, 1987.

Davies, J. A., Lester, M., Milan, S. E., and Yeoman, T. K., A comparison of velocity measurements from the CUTLASS Finland radar and the EISCAT UHF system, Ann. Geophysicae, 17, 892902, 1999.

Eglitis, P. E. and Robinson, T. R., Investigations of the phase speed and spectral width of high latitude plasma irregularities, Adv. Space Res., 22, 1361-1364, 1998.

Farley, D. T., A plasma instability resulting in field-aligned irregularities in the ionosphere, J. Geophys. Res., 63, 6083-6097, 1963.

Fejer, B. G., Farley, D. T., Balsley, B. B., and Woodman, R. F., Vertical structure of the VHF backscattering region in the equatorial electrojet and the gradient drift instability, J. Geophys. Res., 80, 1313-1324, 1975.

Fejer, B. G., Providakes, J. F., and Farley, D. T., Theory of plasma 
waves in the auroral E region, J. Geophys. Res., 89, 7487-7494, 1984.

Greenwald, R. A., Baker, K. B., Dudeney, J. R., Pinnock, M., Jones, T. B., Thomas, E. C., Villain, J.-P., Cerisier, J.-C., Senior, C., Hanuise, C., Hunsucker, R. D., Sofko, G., Koehler, J., Nielsen, E., Pellinen, R., Walker, A. D. M., Sato, N., and Yamagishi, H., DARN/SuperDARN: A global view of the dynamics of highlatitude convection, Space Sci. Rev., 71, 761-796, 1995.

Haldoupis, C., A review on radio studies of auroral E-region ionospheric irregularities, Ann. Geophysicae, 7, 239-258, 1989.

Hall, G. E., MacDougall, J. W., St-Maurice, J.-P., Moorcroft, D. R., and Manson, A. H., Super Dual Auroral Radar Network observations of meteor echoes, J. Geophys. Res., 102, 14603-14614, 1997.

Hamza, A. M. and St-Maurice, J.-P., A turbulent theoretical framework for the study of current-driven E region irregularities at high latitudes. Basic derivation and application to gradient-free situations, J. Geophys. Res., 98, 11587-11599, 1993.

Hanuise, C., Villain, J. P., Cerisier, J. C., C. Senior, Ruohoniemi, J. M., Greenwald, R. A., and Baker, K. B., Statistical study of highlatitude E-region Doppler spectra obtained with the SHERPA HF radar, Ann. Geophysicae, 9, 273, 1991.

Hanuise, C., Villain, J.-P., Gresillon, D., Cabrit, B., Greenwald, R. A., and Baker, K. B., Interpretation of HF radar ionospheric Doppler spectra by collective wave scattering theory, Ann. Geophysicae, 11, 29-39, 1993.

Knox, F. B., A contribution to the theory of the production of fieldaligned ionization irregularities in the equatorial electrojet, J. Atmos. Terr. Phys. 26, 239, 1964.

Maeda, K., Tsuda, T., and Maeda, H., Theoretical interpretation of the equatorial sporadic E layers, Phys. Rev. Lett., 11, 406, 1963.

Milan, S. E., Jones, T. B., Robinson, T. R., Thomas, E. C., and Yeoman, T. K., Interferometer evidence for the observation of ground backscatter from behind the cutlass radars, Ann. Geophysicae., 15, 29-39, 1997.
Milan, S. E. and Lester, M., Simultaneous observations at different altitudes of ionospheric backscatter in the eastward electrojet, Ann. Geophysicae, 16, 55-68, 1998.

Milan, S. E. and Lester, M., Spectral and flow angle characteristics of backscatter from decametre irregularities in the auroral electrojets, Adv. Space Res., 23, 1773, 1999.

Milan, S. E., Lester, M., Sato, N., Takizawa, H., and Villain, J.-P., Investigation of the relationship between optical auroral forms and HF radar E region backscatter, Ann. Geophysicae, 18, 608617, 2000.

Robinson, T. R., Towards a self-consistent non-linear theory of radar auroral backscatter, J. Atmos. Terr. Phys., 48, 417-422, 1986.

Rogister, A. and D'Angelo, N., Type 2 irregularities in the equatorial electrojet, J. Geophys. Res., 75, 3879-3887, 1970.

St-Maurice, J.-P., Prikryl, P., Danskin, D. W., Hamza, A. M., Sofko, G. J., Koehler, J. A., Kustov, A., and Chen, J., On the origin of narrow non-ion- acoustic coherent radar spectra in the highlatitude E region, J. Geophys. Res., 99, 6447-6474, 1994.

Sudan, R. N., Akinrimisi, J., and Farley, D. T., Generation of small scale irregularities in the equatorial electrojet, J. Geophys. Res., 78, 240-248, 1973.

Villain, J.-P., Greenwald, R. A., Baker, K. B., and Ruohoniemi, J. M., HF radar observations of $E$ region plasma irregularities produced by oblique electron streaming, J. Geophys. Res., 92, 12327-12342, 1987.

Villain, J.-P., Hanuise, C., Greenwald, R. A., Baker, K. B., and Ruohoniemi, J. M., Obliquely propagating ion acoustic waves in the auroral E region: Further evidence of irregularity production by field-aligned electron streaming, J. Geophys. Res., 95, 7833-7846, 1990.

Whalen, J. A., A quantitative description of the spatial distribution and dynamics of the energy flux in the continuous aurora, J. Geophys. Res., 88, 7155, 1983. 